\title{
Chemical bonding in Period 2 homonuclear diatomic molecules: a comprehensive relook
}

\author{
A DAS and E ARUNAN* (D \\ Department of Inorganic and Physical Chemistry, Indian Institute of Science, Bangalore 560012, Karnataka, \\ India \\ E-mail: arunan@iisc.ac.in
}

MS received 14 October 2019; revised 28 October 2019; accepted 30 October 2019; published online 5 December 2019

\begin{abstract}
Theoretical and experimental studies of bonding in the main group homonuclear diatomic molecules have been pursued for many years, and they possess serious challenges for scientists. Most of the early experimental work have been carried out by Herzberg. ${ }^{1,2}$ We take a relook at the bonding motifs of Period 2 homonuclear diatomic molecules (from $\mathrm{Li}_{2}$ to $\mathrm{Ne}_{2}$ ) using varieties of quantum chemical tools, commonly used for intermolecular bonding/interactions now. The methods employed include Atoms in Molecules (AIM), Non-covalent Index plot (NCI), Electrostatic potential (ESP), and Potential Acting on one Electron in a Molecule (PAEM). The spectroscopic constants i.e., equilibrium bond distances $\left(\mathrm{r}_{\mathrm{e}}\right)$, harmonic frequencies $(\omega)$, bond dissociation energies $\left(\mathrm{D}_{\mathrm{e}}\right)$ have all been evaluated using high-level ab initio methods and critically compared with the experimental results. Multi-reference calculations (CASSCF) on $\mathrm{B}_{2}$ and $\mathrm{C}_{2}$ have been carried out as they have a large number of low lying electronic states. Bonding within these homonuclear diatomic molecules show all the diversities that are encountered in inter/intra-molecular bonding in chemistry. Based on the AIM analysis, these 8 homonuclear diatomic molecules could be divided into three different groups, based on the correlation between binding energy and the electron density at the bond critical point. However, PAEM/ESP analysis allows us to analyse all eight of them as one group having a good correlation between binding energy and the PAEM/ESP at the critical point between the two atoms. Our results highlight the arbitrariness in relying on some computational tools to characterize a bond as covalent (shared) or ionic/electrostatic (closed). In contrast, they also show the usefulness of the various methods in exploring similarities and differences in bonding. We propose that from $\mathrm{Li}_{2}$ to $\mathrm{Ne}_{2}$, all homonuclear diatomic molecules are bound by 'chemical bonds'.
\end{abstract}

Keywords. Covalency; Iconicity; van der Waals interaction; Atoms in molecules; electrostatic potential.

\section{Introduction}

Bonding within a molecule is generally considered to be well understood and there has been a greater focus on intermolecular bonding involving all group elements in the last decade or so. Until recently, all intermolecular interactions (chemists were hesitant to say intermolecular bonding) were divided into hydrogen bonding and van der Waals interactions and one can already see the confusion in terminology. Hydrogen bonding could readily be recognized in $\mathrm{H}_{2} \mathrm{O}$ and DNA, the molecules of life. However, it was not so simple to understand, leading to a continuous debate on the nature of hydrogen bonding. At the beginning of this decade, IUPAC came up with a modern definition of the hydrogen bond. ${ }^{3,4}$ With the periodic table having 118 elements today, it is but natural to ask why only 'hydrogen bond'. This question has now led to the observation of halogen bonding, ${ }^{5-8}$ chalcogen bonding, ${ }^{9-12}$ pnictogen bonding, ${ }^{13-15}$ carbon/tetrel bonding, ${ }^{16-20}$ triel bonding ${ }^{21}$ and also lithium ${ }^{22,23}$ and beryllium bonding. ${ }^{24,25}$ Though, all these names have been given, the forces leading to these bonds are all the same. Electrostatic interactions between permanent

*For correspondence

Electronic supplementary material: The online version of this article (https://doi.org/10.1007/s12039-019-1707-5) contains supplementary material, which is available to authorized users. 
and induced multipoles, dispersion, exchange repulsion and charge-transfer/covalency all contribute to varying extents. It is generally assumed that all but the last terms are 'physical forces' and covalency is a 'chemical force'. For terminology, chemical force led to 'chemical bond' formation and physical forces seem to have led to 'interactions', perhaps just confusion.

It dawned on us recently that bonding in Period 2 homonuclear diatomic molecules could cover this whole range found in inter/intra-molecular bonding, providing us a motive for this relook. The precise bonding nature of Period 2 diatomic molecules $\left(\mathrm{Li}_{2}\right.$ to $\mathrm{Ne}_{2}$ ) is quite intriguing. A large variety of spectroscopic phenomenon is observed for these diatomic molecules, and the accurate description of the bonding nature is of principal importance. Interestingly, despite being their small size, these molecules are "tough nut to crack" by theoreticians and experimentalists. In terms of high-level theoretical calculations, there are a large number of papers and reviews dealing exclusively or predominately with these molecules, in the literature. $^{26-35}$

The lithium dimer $\left(\mathrm{Li}_{2}\right)$ is the second smallest stable homonuclear dimer next to $\mathrm{H}_{2}$. Spectra of $\mathrm{Li}_{2}$ were observed and analysed in the 1930s. The evidence of Bose-Einstein Condensate in ${ }^{7} \mathrm{Li}_{2}$ by Bradley and coworkers $^{36,37}$ in 1995 has drawn a substantial amount of interest in this system. It is considered a covalent molecule, though the bond is much weaker $(82 \mathrm{~kJ} / \mathrm{mol})$ than the covalent bond in $\mathrm{H}_{2}(436 \mathrm{~kJ} / \mathrm{mol})$.

The study of the next simplest dimer $\left(\mathrm{Be}_{2}\right)$, was carried out by Herzberg. ${ }^{38}$ These attempts failed to produce $\mathrm{Be}_{2}$ and resulted only in observations of beryllium oxide (BeO). ${ }^{39}$ Bondybey and English ${ }^{40}$ first reported the gas phase spectrum in 1984, and established the fact that ground state of $\mathrm{Be}_{2}$ is not repulsive with $\mathrm{Be}-\mathrm{Be}$ bond distance is $2.45 \AA$. In 2009 Merritt, Bondybey and Heaven ${ }^{41}$ with the advent of pulsed laser ablation techniques recorded and analysed all the bound vibrational levels of $\mathrm{Be}_{2}$. Interestingly, the $\mathrm{Be} \cdot \cdots \mathrm{Be}$ bond was neither like $\mathrm{Li}_{2}$ 'covalent' nor like $\mathrm{Ne}_{2}$ 'van der Waals interaction'. It is precisely for this reason that 'a hydrogen bond' was proposed i.e. it was neither as strong as the $\mathrm{O}-\mathrm{H}$ covalent bond in $\mathrm{H}_{2} \mathrm{O}$ nor as week as the 'van der Waals interaction'.

Boron dimer $\left(\mathrm{B}_{2}\right)$ was first experimentally observed in 1940 by Douglas and Herzberg. ${ }^{42}$ In a discharge in helium with a trace amount of boron trichloride, they could establish that $\mathrm{B}_{2}$ was a stable molecule. On the basis of molecular orbital theory Douglas and Herzberg tentatively assigned this to the ${ }^{3} \Sigma_{\mathrm{u}}^{-}-{ }^{3} \Sigma_{\mathrm{g}}^{-}$transition. The optical absorption and ESR spectrum of $\mathrm{B}_{2}$ reported by Graham and Weltner in 1976 confirm
${ }^{3} \sum_{\mathrm{g}}^{-}$ground state. ${ }^{43}$ Recent theoretical calculations on $\mathrm{B}_{2}$ using fairly large basis sets and electron correlation established that the ground state of $\mathrm{B}_{2}$ was ${ }^{3} \Sigma_{\mathrm{g}}^{-}$. 4,45

There is considerable interest in the nature of the bonding in diatomic carbon $\left(\mathrm{C}_{2}\right)$. It has been observed during the photodissociation of acetylene and can be formed by the direct reaction of the $\mathrm{C}\left({ }^{3} \mathrm{P}\right)$ atom with $\mathrm{CH}^{46-49}$ The spectroscopy of low lying electronic state is well known. ${ }^{50-53}$ The $\mathrm{C}_{2}$ molecule has been variously described as having a double bond, ${ }^{54}$ triple bond $^{55}$ or a quadruple bond. ${ }^{56,57}$ The nature of bonding in $\mathrm{C}_{2}$ is still debated.

The most strongly bound diatom, $\mathrm{N}_{2}$ certainly belongs to the most extensively studied systems. There are numerous studies on its ground state, lowest triplet and quintet states. Spectroscopic data and early quantum chemical calculations have been comprehensively reviewed by Lofthus and Krupenie ${ }^{58}$ and Huber. ${ }^{59}$ On the other hand, owing to the larger number of valence electrons, the number of low lying bound excited states of $\mathrm{O}_{2}$ is much smaller than $\mathrm{N}_{2}$ or $\mathrm{C}_{2}$.

The interest in excited states of $\mathrm{O}_{2}$ is large because of its importance in terrestrial chemistry and biochemistry. The most comprehensive review of the spectroscopy of $\mathrm{O}_{2}$ has been given by Krupenie ${ }^{60}$ and Matsunaga and Watanabe. ${ }^{61}$ Further experimental data can be found in a book of Huber. ${ }^{59}$ Electronic structure and spectrum of $F_{2}$ molecule have been published in early 1920 's. ${ }^{62,63}$ Raman spectrum of $\mathrm{F}_{2}$ was measured by Andrychuk. ${ }^{64}$ Absorption spectra of homopolar diatomic rare gas $\mathrm{Ne}_{2}$ has been studied by Tanaka and Yoshino in 585-760 ̊ region. ${ }^{65}$ They have identified 12 discrete band systems. The ground state of $\mathrm{Ne}_{2}$ is stable with potential depth of $D_{e}=30.2 \mathrm{~cm}^{-1}$.

We have also included $\mathrm{LiH}$ and $\mathrm{HF}$ (Heteronuclear dimers) in this review because the nature of interaction of these diatomic hydrides are different, former being 'more ionic' and the latter being 'more covalent'. The bonding in second row hydrides covers the complete range of Pauling's definition of ionic-covalent character. $^{66}$ Thus the dipole moment of HLi is $-5.882 \mathrm{D}$ in the sense $\mathrm{H}^{-} \mathrm{Li}^{+}$, while for HF the polarity is reversed, i.e., in the sense $\mathrm{H}^{+} \mathrm{F}^{-}$, and the magnitude of the dipole moment is $1.8195 \mathrm{D}^{67}$

This manuscript focuses on the bonding nature of homonuclear diatomic molecules based on the popular quantum chemistry tools. Much of the chemical information in this paper is derived from the analysis of molecular electron density $(\rho)$. Bader ${ }^{68}$ and Popelier ${ }^{69}$ employed the electron density to build a rigorous QM basis for the definition of an atom in a molecule (AIM). The AIM theory primarily looks at the electron 
density at every point around the nuclei of a molecule. Based on the electron density, we have calculated several other properties like an electronic population of the atom, delocalization index, etc. The AIM theory is a powerful method to predict the nature of the bond based on the electron densities at the bond critical point. In particular, several methods have been developed to characterize, intermolecular interactions as 'closed-shell' and 'shared-shell', and these can be related to 'ionic bond' or 'non-covalent interactions' and 'covalent bond' in chemistry. ${ }^{70,71}$ It would not be an exaggeration to point out that understanding 'hydrogen bond' has motivated some of these efforts. The non-covalent index plot is primarily designed to study weak bonding interactions. ${ }^{72-74}$

In this manuscript, we report results for the homonuclear diatomic molecules from Period 2 using all these methods. Moreover, we have calculated potential acting on one electron molecular orbitals (PAEM-MO) $)^{75-78}$ and the electrostatic potential (ESP) for the diatomic molecules. Interestingly, these methods provide a universal way to look at the bonds holding the Period 2 atoms together when they form a diatomic molecule. Discussion on HLi and HF have been included for comparison.

\section{Computational details}

Homonuclear diatomic molecules of Period 2 and HLi/ HF were optimized using DFT (B3LYP), MP2, CCSD, and CCSD $(\mathrm{T})$ methods with different basis sets. The calculations were performed using Gaussian $09^{79}$ program. Multireference calculations were performed using Molpro 2015.1 version. ${ }^{80}$ Atoms in molecules $(\mathrm{AIM})^{68}$ theory has been used to carry out electron density topological studies using AIMALL program. ${ }^{81}$ The Wiberg bond order of the diatomic molecules have been calculated with the help of NBO 6.0. ${ }^{82}$ Natural Resonance Theory (NRT) ${ }^{83}$ was used to calculate the fraction of ionicity and covalency in the homonuclear diatomics and also $\mathrm{LiH}$ and $\mathrm{HF}$ molecules. By using the Multiwfn ${ }^{84}$ program the Non Covalent Index $(\mathrm{NCI})^{74}$ plots were obtained with two functions, function 1 (on the $\mathrm{X}$-axis) is the multiplication of the sign of the second eigenvalue $\left(\lambda_{2}\right)$ of electron density Hessian matrix with the electron density $(\rho) \operatorname{sign}\left(\lambda_{2}\right)^{*} \rho$ )] and function 2 (on Y-axis) reduced density gradient. NCI plot provides a way to differentiate between covalent bonds and van der Waals interactions. Potential acting on one electron in a molecule (PAEM) is also able to capture the differences between covalent and van der Waals interaction based on molecular orbital viewpoint. PAEM calculations are carried out using Multiwfn 3.6 program. ${ }^{84}$

\section{Results and Discussion}

\subsection{Geometric parameters}

The results from our calculations are presented in Tables 1,2, and 3. The equilibrium bond distances and Wiberg bond order are presented in Table 1 calculated at $\operatorname{CCSD}(\mathrm{T})($ Full)/aug-cc-pVTZ level, along with the experimental bond distances. They are in very good agreement, except for $\mathrm{Be}_{2}$, which has a deviation of more than $0.1 \AA$. It was noted that the results for $\mathrm{Be}_{2}$ vary widely with the level and basis set. The results at many different levels of calculations are given in the supporting information (Table ST1, Supplementary Information).

The bond distances are compared with twice the atomic, covalent and van der Waals radii and these lead to some trivial and some non-trivial conclusions. In $\mathrm{Ne}_{2}$, the bond distance is very close to the sum of van der Waals radii. The only other molecule for which the experimental bond distance is close to the sum of radii is $\mathrm{F}_{2}$ and for this, the agreement is with the sum of atomic radii and not with the sum of covalent radii. From $\mathrm{B}_{2}$ to $\mathrm{O}_{2}$, all have multiple bonds and hence appropriate covalent radii should be compared. As mentioned earlier, $\mathrm{Be}_{2}$ has a bond distance that is less than the sum of its van der Waals radii but more than that of the covalent radii.

The Wiberg bond order calculated for these diatomic molecules vary from 0 for $\mathrm{Ne}_{2}$ to 3.661 for $\mathrm{C}_{2}$. For comparison, HLi, which is a typical ionic bonded molecule has a bond order of 0.2851 and HF, thought to be a 'covalent' molecule has a bond order of 0.6868 . Beyond, $\mathrm{Ne}_{2}$, the lowest bond order is calculated for $\mathrm{Be}_{2}, 0.1615$.

It is interesting to note that the highest level of calculations, $\operatorname{CCSD}(\mathrm{T})($ Full), are able to get the interatomic distances very close to the experimental values, for all the diatomic molecules of Period 2, irrespective of the nature of bonding. Clearly, modern quantum theory can explain chemistry in all circumstances well, despite the continuous debate on the nature of 'chemical bond', including that present in the simplest of all molecules, $\mathrm{H}_{2} .{ }^{85}$ The devil, indeed, is in the detail. We submit that all the atoms considered in this work are chemical, and all these homonuclear diatomic molecules are held together by 'chemical bonds'. 
Table 1. Electronic ground state, Wiberg bond order, equilibrium bond distances for Period 2 dimers (aug-cc-pVTZ) and the sum of atomic, covalent and van der Waals radii (values are in $\AA$ )*.

\begin{tabular}{lccccccc}
\hline & Ground state & Wiberg bond order & CCSD(T) (full) & Expt. & Atomic & Covalent & van der Waals \\
\hline $\mathrm{Li}_{2}$ & ${ }^{1} \sum_{\mathrm{g}}^{+}$ & 1.0005 & 2.667 & 2.673 & 3.04 & 2.66 & 3.64 \\
$\mathrm{Be}_{2}$ & ${ }^{1} \sum_{\mathrm{g}}^{+}$ & 0.1615 & 2.343 & 2.453 & 2.25 & 2.04 & 3.06 \\
$\mathrm{~B}_{2}$ & ${ }^{3} \sum_{\mathrm{g}}^{-}$ & 2.2734 & 1.587 & 1.590 & 1.66 & $1.70 / 1.56$ & 4.16 \\
$\mathrm{C}_{2}$ & ${ }^{1} \sum_{\mathrm{g}}^{+}$ & 3.6610 & 1.245 & 1.243 & 1.54 & $1.50 / 1.34 / 1.20$ & 3.70 \\
$\mathrm{~N}_{2}$ & ${ }^{1} \sum_{\mathrm{g}}^{+}$ & 3.0332 & 1.101 & 1.098 & 1.42 & $1.42 / 1.20 / 1.08$ & 3.08 \\
$\mathrm{O}_{2}$ & ${ }^{3} \sum_{\mathrm{g}}^{-}$ & 2.0248 & 1.209 & 1.208 & 1.30 & $1.26 / 1.14$ & 2.80 \\
$\mathrm{~F}_{2}$ & ${ }^{1} \sum_{\mathrm{g}}^{+}$ & 1.0044 & 1.414 & 1.412 & 1.42 & 1.28 & 2.70 \\
$\mathrm{Ne}_{2}$ & ${ }^{1} \sum_{\mathrm{g}}^{+}$ & 0.0000 & 2.976 & $3.091 *$ & 3.08 & 1.34 & 3.20 \\
$\mathrm{HLi}$ & ${ }^{1} \sum^{+}$ & 0.2851 & 1.592 & 1.595 & 2.30 & 1.65 & 3.02 \\
$\mathrm{HF}$ & ${ }^{1} \sum^{+}$ & 0.6868 & 0.919 & 0.918 & 1.49 & 0.96 & 2.55 \\
\hline
\end{tabular}

$* \operatorname{Ref}^{86}$.

Bond lengths are taken from NIST database except where a superscript appear.

All radii are taken from the book 'Elements' by Emsley. ${ }^{87}$

Table 2. Vibrational frequencies $\left(\mathrm{cm}^{-1}\right)$ (without anharmonic correction) for Period 2 dimers (aug-cc-pVTZ).

\begin{tabular}{llllccc}
\hline & DFT & MP2 & CCSD & CCSD $(T)$ & CCSD (T,full) & *Experiment \\
\hline $\mathrm{Li}_{2}$ & 343 & 341 & 345 & 345 & 343 & 351 \\
$\mathrm{Be}_{2}$ & 287 & 108 & 29 & 207 & 384 & 271 \\
$\mathrm{~B}_{2}$ & 1006 & 1098 & 1028 & 1038 & 1083 & 1051 \\
$\mathrm{C}_{2}$ & 1875 & 1875 & 1877 & 1841 & 1878 & 1855 \\
$\mathrm{~N}_{2}$ & 2448 & 2187 & 2419 & 2340 & 2370 & 2358 \\
$\mathrm{O}_{2}$ & 1626 & 1455 & 1658 & 1575 & 1593 & 1580 \\
$\mathrm{~F}_{2}$ & 1050 & 1004 & 1011 & 917 & 925 & 892 \\
$\mathrm{Ne}_{2}$ & 30 & 29 & 30 & 33 & 38 & 30 \\
$\mathrm{HLi}$ & 1418 & 1414 & 1386 & 1387 & 1405 & 1405 \\
$\mathrm{HF}$ & 4073 & 4123 & 4170 & 4126 & 4141 & 4138 \\
\hline
\end{tabular}

*Experimental vibrational frequencies are taken from NIST database.

Table 3. Dissociation energies $(\mathrm{kJ} / \mathrm{mol})$ for Period 2 dimers (aug-cc-pVTZ). Zero-point energies are given in the parenthesis.

\begin{tabular}{lllllll}
\hline & \multicolumn{1}{c}{ DFT } & \multicolumn{1}{c}{ MP2 } & \multicolumn{1}{c}{ CCSD } & \multicolumn{1}{c}{ CCSD(T) } & \multicolumn{1}{c}{ CCSD (T,full) } & \multicolumn{1}{c}{ Experiment } \\
\hline $\mathrm{Li}_{2}$ & $87.4(2.1)$ & $72.3(2.0)$ & $99.6(2.1)$ & $99.6(2.1)$ & $103.4(2.1)$ & $82.4^{\mathrm{a}}$ \\
$\mathrm{Be}_{2}$ & $17.8(1.7)$ & $4.4(0.6)$ & $0.7(0.2)$ & $4.2(1.2)$ & $34.7(2.3)$ & $11.1+0.02^{\mathrm{b}}$ \\
$\mathrm{B}_{2}$ & $251.2(6.0)$ & $266.0(6.6)$ & $225.3(6.1)$ & $225.3(6.2)$ & $247.5(6.5)$ & $290^{\mathrm{c}}$ \\
$\mathrm{C}_{2}$ & $498.9(11.2)$ & $634.5(11.2)$ & $506.9(11.2)$ & $506.8(11.0)$ & $459.1(11.2)$ & $618.3 \pm 15.4^{\mathrm{c}}$ \\
$\mathrm{N}_{2}$ & $957.8(14.6)$ & $964.9(13.1)$ & $873.9(14.5)$ & $873.5(14.0)$ & $897.8(14.2)$ & $944.84 \pm 0.10^{\mathrm{c}}$ \\
$\mathrm{O}_{2}$ & $515.3(9.7)$ & $531.3(8.7)$ & $448.9(9.9)$ & $448.4(9.4)$ & $462.5(9.5)$ & $498.36 \pm 0.17^{\mathrm{c}}$ \\
$\mathrm{F}_{2}$ & $155.2(6.3)$ & $175.1(6.0)$ & $123.3(6.0)$ & $122.4(5.5)$ & $128.7(5.5)$ & $158.670 \pm 0.096^{\mathrm{c}}$ \\
$\mathrm{Ne}_{2}$ & $0.1(0.2)$ & $0.3(0.2)$ & $0.4(0.2)$ & $0.4(0.2)$ & $0.6(0.2)$ & $0.35^{\mathrm{d}}$ \\
$\mathrm{HLi}$ & $244.8(8.5)$ & $216.6(8.5)$ & $238.1(8.3)$ & $238.1(8.3)$ & $243.7(8.4)$ & $238.039 \pm 039^{\mathrm{c}}$ \\
$\mathrm{HF}$ & $582.0(24.4)$ & $601.1(24.7)$ & $574.4(24.9)$ & $574.4(24.7)$ & $579.0(24.8)$ & $569.680 \pm 0.011^{\mathrm{c}}$ \\
\hline
\end{tabular}

${ }^{\mathrm{a}} \operatorname{Ref}^{88},{ }^{\mathrm{b}} \operatorname{Ref}^{41},{ }^{\mathrm{c}} \operatorname{Ref}{ }^{89},{ }^{\mathrm{d}} \operatorname{Ref}^{86}$. 
Table 4. Types and characteristic of critical points (cps) based on the rank and signature of the hessian matrix.

\begin{tabular}{lll}
\hline (Rank, Signature) & Types of critical points & Curvature \\
\hline$(3,-3)$ & Nuclear critical point (NCP) & All negative, local maxima \\
$(3,-1)$ & Bond critical point (BCP) & Two negative, one positive \\
$(3,+1)$ & Ring critical point (RCP) & One negative, two positive \\
$(3,+3)$ & Cage critical point (CCP) & All positive, local minima \\
\hline
\end{tabular}

\subsection{Vibrational frequencies and dissociation energies}

Theoretical frequencies calculated at various level are compared with experimental values in Table 2. The results are similar to those discussed above and except for a specific problem at CCSD level for $\mathrm{Be}_{2}$, other numbers do look reasonable. A detailed analysis of method and basis set dependencies of $\mathrm{Be}_{2}$ geometry has been provided in Table ST1 (Supplementary Information). Considering the fact that these are harmonic frequencies, most numbers look reasonable. In particular, the values for $\mathrm{Li}_{2}$ and $\mathrm{Ne}_{2}$, in comparison with $\mathrm{Be}_{2}$ highlight an important point. $\mathrm{Li}_{2}$ considered covalent and $\mathrm{Ne}_{2}$ bound by London dispersive forces are both handled well by all methods. However, for $\mathrm{Be}_{2}$, the results show a large variation depending on the methods. Both in terms of distance and vibrational frequency, DFT appears to be doing better than MP2 and CCSD methods for $\mathrm{Be}_{2}$. A detailed discussion on these diatomics is given in the later sections.

The dissociation energies reported for the homonuclear diatomic molecule reinforces the points mentioned above. If one looks for quantitative comparison, the differences between experimental and computed values are somewhat larger compared to data presented in Tables 1 and 2. However, the fact that the dissociation energies, given in Table 3, range from 0 to $1000 \mathrm{~kJ} \mathrm{~mol}^{-1}$ and these are computed reasonably well, shows that the quote "The fundamental laws necessary for the mathematical treatment of a large part of physics and the whole of chemistry are thus completely known, and the difficulty lies only in the fact that application of these laws leads to equations that are too complex to be solved" by Dirac was indeed prophetic. For $\mathrm{N}_{2}, \mathrm{O}_{2}, \mathrm{~F}_{2}$, DFT reproduces the dissociation energies much better than the other methods, especially the CCSD methods. A comparison of the percentage errors are given in the Supplementary Information (see SF1). For HLi and HF calculated dissociation energies from all the methods are in excellent agreement with the experimental values.

\subsection{Atoms in molecules analysis}

Topological study of electron density $(\rho)^{68}$ helps us look deeper into the nature of chemical bonds. Any point in space where all the first-order partial derivative of electron density vanishes is termed as a critical point (cp). The topological feature of such points are characterised in terms of the rank and signature of the Hessian matrix. The rank is defined as the number of non-zero eigenvalues of the Hessian matrix and signature as the algebraic sum of the sign of the non-zero eigenvalues. Based on this a scalar function can have four types of critical points, as shown in Table 4.

Most of the stable nuclear configurations critical points are of rank three. In a few exceptions, degenerate cps with rank $<3$ are observed. A degenerate critical point is unstable and a small change in electron density caused by slight displacement in nuclear configuration makes it vanish or changes it to stable cps of rank three. We have observed the degenerate critical points with rank 2 in $\mathrm{C}_{2}$ for $\operatorname{CCSD}(\mathrm{T})$ wave functions. The AIM parameters calculated for the diatomic molecules have been summarized in Table 5. The method and basis set dependence of these parameters are summarized in Tables ST2-ST9 (Supplementary Information). Major conclusions from this analysis do not depend on the method and basis set. Some details do vary and they are discussed in this section.

To understand how the electron density varies between the two atoms, having a chemical bond, we have plotted electron density $(\rho)$ and gradient norm of electron density $(|\nabla \rho|)$ variation along the internuclear axis of $\mathrm{N}_{2}$ (Figure 1). Electron density at the midpoint of $\mathrm{N}-\mathrm{N}$ bond is minimum, so its first derivative goes to zero at that point resulting in a bond critical point.

\subsection{Electron density vs. binding energy correlation}

Bader $^{68}$ showed that the electron density at BCP is a good indicator of strength of the bonds. In this review, 
Table 5. Properties calculated from atoms in molecules analysis. Wave functions used for the calculations are evaluated at CCSD (T)(full)/aug-cc-pVTZ level. (In case of $\mathrm{C}_{2}$ wave function at CCSD/aug-cc-pVTZ level used for calculation).

\begin{tabular}{lcccccccr}
\hline Diatomic molecules & $\rho(\mathrm{r})$ & $\nabla^{2} \rho$ & $\lambda_{1}=\lambda_{2}$ & $\lambda_{3}$ & $\left|\lambda_{1}\right| / \lambda_{3}$ & $\mathrm{~V}$ & $\mathrm{G}$ & $\mid \mathrm{Vl} / \mathrm{G}$ \\
\hline$* \mathrm{Li}_{2}$ & 0.0139 & +0.0089 & -0.0054 & +0.0197 & 0.274 & -0.0063 & +0.0043 & 1.47 \\
$\mathrm{Be}_{2}$ & 0.0373 & -0.0462 & -0.0275 & +0.0088 & 3.125 & -0.0151 & +0.0018 & 8.39 \\
$* \mathrm{~B}_{2}$ & 0.1247 & +0.0839 & -0.0805 & +0.2449 & 0.329 & -0.2582 & +0.1396 & 1.85 \\
$* \mathrm{C}_{2}$ & 0.3160 & -0.0161 & -0.2197 & +0.4232 & 0.519 & -1.0496 & +0.5228 & 2.01 \\
$\mathrm{~N}_{2}$ & 0.7204 & -3.5009 & -1.9419 & +0.3829 & 5.072 & -2.1117 & +0.6182 & 3.42 \\
$\mathrm{O}_{2}$ & 0.5505 & -0.9375 & -1.5281 & +2.1187 & 0.721 & -1.1771 & +0.4713 & 2.50 \\
$\mathrm{~F}_{2}$ & 0.3004 & +0.2013 & -0.7351 & +1.6716 & 0.440 & -0.4720 & +0.2612 & 1.81 \\
$\mathrm{Ne}_{2}$ & 0.0023 & +0.0144 & -0.0025 & +0.0194 & 0.129 & -0.0022 & +0.0029 & 0.76 \\
$\mathrm{HLi}$ & 0.0402 & +0.1704 & -0.0607 & +0.2919 & 0.208 & -0.0431 & 0.0429 & 1.00 \\
$\mathrm{HF}$ & 0.3735 & -3.5009 & -2.6993 & +1.8977 & 1.422 & -1.0381 & 0.0814 & 12.75 \\
\hline
\end{tabular}

*Presence of Non-nuclear attractor (NNA), with two bond critical points $(\mathrm{BCP}), \rho(\mathrm{r})$ is the electron density, $\nabla^{2} \rho$ is Laplacian of electron density, $\lambda_{1}$ and $\lambda_{3}$ are the first and third eigenvalue of Hessian matrix, all at intermolecular BCP, V potential energy density, G kinetic energy density. All the quantities are in atomic units.
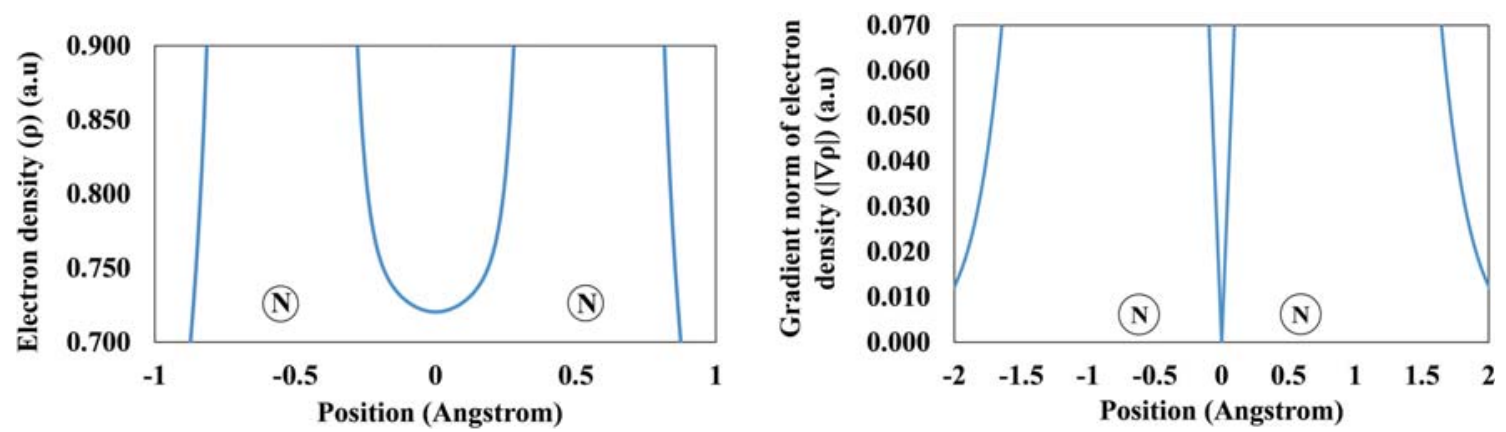

Figure 1. Electron density $(\rho)$, gradient norm of electron density $(|\nabla \rho|)$ plot for $\mathrm{N}_{2}$. (Y-axis: Values are in a.u, X-axis: Values are in angstrom).

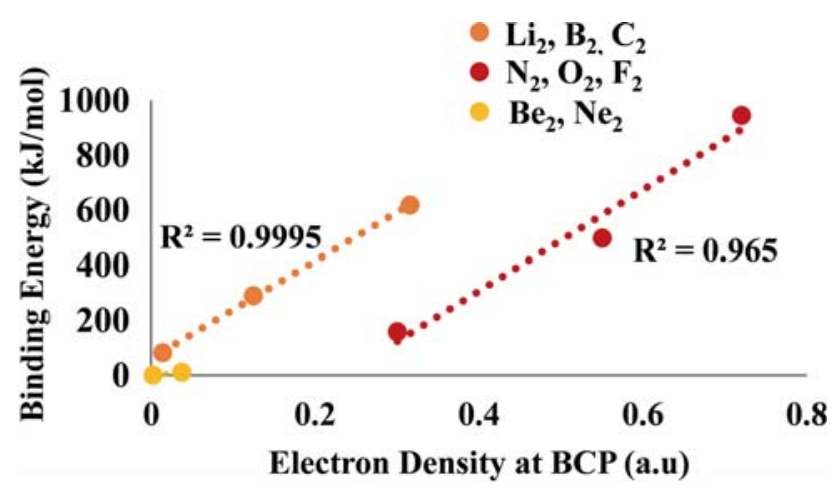

Figure 2. Binding energy $(\mathrm{kJ} / \mathrm{mol})$ vs. electron density plot (a.u) for Period 2 dimers.

we have taken 8 homonuclear diatomic molecules, bonding nature of these diatomic molecules will be discussed in details in the next section. We have divided these diatomic molecules into three different classes. $\mathrm{Li}_{2}, \mathrm{~B}_{2}$, and $\mathrm{C}_{2}$ show non-nuclear attractors (NNA) along the internuclear axis. $\mathrm{Ne}_{2}$ and $\mathrm{Be}_{2}$ are quite similar, both have dispersion dominated interactions. On the other hand, $\mathrm{N}_{2}, \mathrm{O}_{2}$ and $\mathrm{F}_{2}$ are typical examples of covalent bonds. In can be seen from Figure 2 that such a division is logical and within these three classes of molecules, binding energy correlates well with the electron density. Without such grouping, the correlation between electron density and binding energy is poor leading to a decreased $\mathrm{R}^{2}$ value of 0.8 , as shown in Figure SF2 (Supplementary Information).

\subsection{Differentiation between closed and shared shell interaction based on atoms in molecules topological analysis}

Sign of Laplacian at the bond critical point has been used to differentiate between closed and shared shell interaction. Closed shell interactions are characterized by positive Laplacian $\left(\nabla^{2} \rho>0\right)$ whereas negative Laplacian $\left(\nabla^{2} \rho<0\right)$ indicates shared shell interaction. Soon, it was realized that this criterion could be misleading and Sosa et al., ${ }^{70}$ introduced another criterion based on the ratio of $\left|\lambda_{1}\right| \lambda_{3}$ i.e., the first and 
Table 6. Defined parameters to differentiate between kinds of interaction from Atoms in Molecules theory.

\begin{tabular}{llll}
\hline Criterions & \multicolumn{1}{c}{$\nabla^{2} \rho$} & \multicolumn{1}{c}{$\left|\lambda_{1}\right| / \lambda_{3}$} & \multicolumn{1}{c}{$\mid \mathrm{Vl} / \mathrm{G}$} \\
\hline Closed (Ionic, van der Waals) & Positive & $0-0.25$ & $0-1.00$ \\
Shared (Covalent) & Negative & 1 and above & 2.00 and above \\
Intermediate & - & $0.25-1.00$ & $1.00-2.00$ \\
\hline
\end{tabular}

third eigenvalue of the Hessian matrix. For diatomic molecules, $\lambda_{1}$ and $\lambda_{2}$ are degenerate. $\left|\lambda_{1}\right| / \lambda_{3}$ less than 0.25 indicated a closed shell and greater than 1 indicated a shared shell interaction. Values in between 0.25 and 1 are regarded as interaction of intermediate kind. Cremer and Karka ${ }^{71}$ proposed another criterion based on potential $(\mathrm{V})$ and kinetic $(\mathrm{G})$ energy density ratio. For closed-shell interaction, $|V| / G<1$ and for shared shell $|\boldsymbol{V}| \boldsymbol{G}>2$. $|\boldsymbol{V}| \boldsymbol{G}$ in between the limits proposed as intermediate kind of interaction. For the sake of simplicity, we have tabulated all these criteria in Table 6 and their applications to the diatomic molecules in Table 7.

The data presented in Table 7 highlight the arbitrariness of these criteria for the 8 homonuclear diatomic molecules from Period 2. For HLi and HF, all three criteria lead to the expected outcome, though for $\mathrm{HLi}, \mathrm{IVI} / \mathrm{G}$ is at the border between closed and intermediate. Only for three of the eight cases, $\mathrm{Be}_{2}, \mathrm{~N}_{2}$ and $\mathrm{Ne}_{2}$, all three criteria lead to the same conclusion. However, $\mathrm{Be}_{2}$ is shown to have 'shared-shell interaction' and $\mathrm{Ne}_{2}$, as expected, a closed-shell interaction. In the previous section, it was pointed out that $\mathrm{Be}_{2}$ and $\mathrm{Ne}_{2}$ are similar and hence both would have 'closedshell interaction. While it was expected that all the other 7 homonuclear diatomics would have 'shared-

Table 7. Nature of interaction in Period 2 homonuclear dimers using criterions defined in Table 6.

\begin{tabular}{llll}
\hline Criterions & \multicolumn{1}{c}{$\nabla^{2} \rho$} & \multicolumn{1}{c}{$\left|\lambda_{1}\right| / \lambda_{3}$} & \multicolumn{1}{c}{$|\mathrm{V}| / \mathrm{G}$} \\
\hline $\mathrm{Li}_{2}$ & Closed & Intermediate & Intermediate \\
$\mathbf{B e}_{2}$ & Shared & Shared* & Shared \\
$\mathrm{B}_{2}$ & Closed & Intermediate & Intermediate \\
$\mathrm{C}_{2}$ & Shared & Intermediate & Shared \\
$\mathbf{N}_{2}$ & Shared & Shared & Shared \\
$\mathrm{O}_{2}$ & Shared & Intermediate & Shared \\
$\mathrm{F}_{2}$ & Closed & Intermediate & Intermediate \\
$\mathbf{N e}_{2}$ & Closed & Closed & Closed \\
$\mathrm{HLi}$ & Closed & Closed & Closed \\
$\mathrm{HF}$ & Shared & Shared & Shared \\
\hline
\end{tabular}

*In MP2/aug-cc-pVTZ method value is $0.709 ;{ }^{\#}$ The value is 1.004 and it is right at the border of shared and intermediate. shell' interaction, only $\mathrm{N}_{2}$ fulfilled all three criteria. Both $\mathrm{Li}_{2}$ and $\mathrm{F}_{2}$ appear similar, having a 'closed-shell interaction' based on $\nabla^{2} \rho$, and intermediate interaction based on the other two criteria. The $\nabla^{2} \rho$ for $F_{2}$ has a large positive value, indicating electron depletion in bond critical point, the other two criterion falls in the intermediate kind. $\nabla^{2} \rho$ has a large negative value for $\mathrm{O}_{2}$ but $\left|\lambda_{1}\right| \lambda_{3}$ ratio falls in the intermediate range. $\mathrm{IVI} / \mathrm{G}$ ratio is more than 2 irrespective of the nature of wave function. $\mathrm{Li}_{2}, \mathrm{~B}_{2}$ and $\mathrm{C}_{2}$ show NNA along the internuclear axis, so the parameters derived at the BCP may not represent the interaction between the atoms. However, the electron density is nearly flat and the densities at both BCPs and the NNA in between them are very close in value. $\mathrm{Ne}_{2}$ expectedly shows closed-shell interaction in all three parameters. A bar diagram showing $|\lambda| 1 / \lambda 3$ and $\mid \mathrm{Vl} / \mathrm{G}$ for all diatomic molecules is given in Figure SF3 (Supplementary Information).

\subsection{Properties of the atoms}

The Atoms in Molecules approach naturally allows one to estimate the number of electrons within the boundary of atoms in a molecule and compare it with the number of electrons in the independent atom. Such an analysis is presented in Tables 8 and 9 for the homonuclear diatomics without and with non-nuclear attractors in between. This gives a very different picture of all these molecules. $\mathrm{N}_{2}$ with three covalent bonds has the largest percentage of electrons staying within its boundary and that is a very high $78 \%$. Not surprisingly, $\mathrm{Ne}_{2}$ retains almost all the electrons with itself and one has to use more decimals to get an accurate picture, $99.95 \%$. Another surprising result of this analysis is that $\mathrm{Be}_{2}$ has more delocalization (10\%) than $\mathrm{F}_{2}(7 \%)$. Clearly this difference is due to the difference in electronegativity. All the homonuclear diatomic molecules from Period 2, having no NNA, have a small percentage of delocalization.

A similar analysis for the $\mathrm{Li}_{2}, \mathrm{Be}_{2}$ and $\mathrm{C}_{2}$ give results in stark contrast with the other homonuclear 
Table 8. Localization and delocalization data of diatomic molecules without NNA.

\begin{tabular}{lclccc}
\hline Diatomic molecules & N(A) & LI(A) & \%Loc(A) & DI(A,A')/2 & \%Deloc(A,A') \\
\hline $\mathrm{Be}_{2}$ & 4.0 & 3.58 & 90 & 0.42 & 10 \\
$\mathrm{~N}_{2}$ & 7.0 & 5.48 & 78 & 1.52 & 22 \\
$\mathrm{O}_{2}$ & 8.0 & 6.89 & 86 & 1.11 & 14 \\
$\mathrm{~F}_{2}$ & 9.0 & 8.38 & 93 & 0.62 & 7 \\
$\mathrm{Ne}_{2}$ & 10.0 & 9.994 & 99.95 & 0.005 & 0.05 \\
\hline
\end{tabular}

N(A): Average Number of Electrons in Atom A, LI(A): Average Number of Electrons Localized in Atom A, \%Loc(A): Percentage of Average Number of Electrons in Atom A that are Localized in Atom A, DI $\left(\mathrm{A}, \mathrm{A}^{\prime}\right) / 2$ : Average Number of Electrons in Atom A that are Delocalized (Shared) Between Atom A and Other Atoms of Molecule, \% Deloc(A, A'): Percentage of Average Number of Electrons in Atom A That are Shared With Other Atoms of Molecule.

Table 9. Localization and delocalization data of diatomic molecules with NNA. (In case of $\mathrm{C}_{2}$ wave function at CCSD/aug-cc-pVTZ level used for calculation).

\begin{tabular}{lccccc}
\hline Atoms & $\mathrm{N}(\mathrm{A})$ & $\mathrm{LI}(\mathrm{A})$ & \%Loc(A) & DI $\left(\mathrm{A}, \mathrm{A}^{\prime}\right) / 2$ & \%Deloc(A,A') \\
\hline $\mathrm{Li}_{2}$ & 2.37 & 2.07 & 87 & 0.30 & 13 \\
$\mathrm{NNA}\left(\mathrm{Li}_{2}\right)$ & 1.26 & 0.79 & 63 & 0.47 & 37 \\
$\mathrm{~B}_{2}$ & 4.55 & 3.51 & 77 & 1.04 & 23 \\
$\mathrm{NNA}\left(\mathrm{B}_{2}\right)$ & 0.91 & 0.22 & 24 & 0.69 & 76 \\
${ }^{*} \mathrm{C}_{2}$ & 5.61 & 4.51 & 80 & 1.10 & 20 \\
${ }^{*} \mathrm{NNA}\left(\mathrm{C}_{2}\right)$ & 0.78 & 0.16 & 20 & 0.62 & 80 \\
\hline
\end{tabular}

diatomic molecules from Period 2. For these molecules, the NNA is treated as a nucleus as well and one could calculate the percentage of electrons localized and delocalized on nuclei and NNA, as shown in Table 9. Popelier has pointed out that electron density in these non-nuclear attractors are mostly delocalized. In case of the $\mathrm{Li}_{2}, 37 \%$ of electron density is delocalized in the NNA. Electron delocalization percentages in NNA of $\mathrm{B}_{2}$ and $\mathrm{C}_{2}$ are $76 \%$ and $80 \%$ respectively.

Electrons on boron atoms are the most delocalized (23\%) Table 9. Properties of these NNA's are provided in Table ST10 (Supplementary Information). One could also compare the localized electrons in the two atoms with the total number of electrons, after molecule formation. This leads to the percentage delocalization of $31 \%$ for $\mathrm{Li}_{2}, 29.8 \%$ for $\mathrm{B}_{2}$ and $24.8 \%$ for $\mathrm{C}_{2}$, all higher than the other molecules. Though the bonding in these molecules has been interpreted as two bonds between the atom and NNA, we propose that the presence of NNA itself could be treated as the historic covalent bond, showing accumulation of electrons between the two atoms.
In order to ensure that the presence of NNA is not method/basis set dependent, we have evaluated the wave functions from several different levels of theory and basis sets. The presence of NNA in $\mathrm{Li}_{2}$ can be seen irrespective of the methods and basis sets (Table 10), whereas for $\mathrm{B}_{2}$ and $\mathrm{C}_{2}$ presence and number of NNA's are method and basis set dependent (Tables 11 and 12). The highest single reference calculation at CCSD(T) level, confirms the presence of NNA for both $\mathrm{C}_{2}$ and $\mathrm{B}_{2}$. However, both $\mathrm{B}_{2}$ and $\mathrm{C}_{2}$, have fairly large number of low lying electronic states (Table ST12, Supplementary Information). Hence, to resolve this ambiguity we invoked the multi-reference CASSCF calculations. These results are presented in Table 13. At the highest level of multi-reference calculations carried out in this work, CASSCF with augcc-pvQZ basis set, there is no NNA for both these molecules! Along with the diatomic molecules, in a few rare cases NNA $(3,-3)$ critical points are observed such as lithium, sodium and beryllium clusters. ${ }^{90,91}$ Experimentally NNAs are recognized in solid silicon ${ }^{92}$ and beryllium. ${ }^{93}$ In 2011, Platts et al., reported the presence NNA in the case of dimeric magnesium compound in $\mathrm{Mg}-\mathrm{Mg}$ region. ${ }^{94}$ 
Table 10. Dependence on methods and basis sets for the number of non-nuclear attractors (NNA) in $\mathrm{Li}_{2}$.

\begin{tabular}{|c|c|c|c|c|c|}
\hline & $\mathrm{HF}$ & DFT(B3LYP) & MP2 & CCSD & $\operatorname{CCSD}(\mathrm{T})$ \\
\hline $6-311 G++(d, p)$ & 1 & 1 & 1 & 1 & 1 \\
\hline cc-pVDZ & 1 & 1 & 1 & 1 & 1 \\
\hline cc-pVTZ & 1 & 1 & 1 & 1 & 1 \\
\hline cc-pVQZ & 1 & 1 & 1 & 1 & 1 \\
\hline aug-cc-pVDZ & 1 & 1 & 1 & 1 & 1 \\
\hline aug-cc-pVTZ & 1 & 1 & 1 & 1 & 1 \\
\hline aug-cc-pvQZ & 1 & 1 & 1 & 1 & 1 \\
\hline
\end{tabular}

Table 11. Dependence on methods and basis sets for the number of non-nuclear attractors (NNA) in $\mathrm{B}_{2}$.

\begin{tabular}{lccccc}
\hline & HF & DFT(B3LYP) & MP2 & CCSD & CCSD(T) \\
\hline 6-311G++(d,p) & 0 & 0 & 2 & 0 & 2 \\
cc-pVDZ & 2 & 2 & 2 & 0 & 2 \\
cc-pVTZ & 2 & 1 & 1 & 1 & 1 \\
cc-pVQZ & 2 & 2 & 2 & 2 & 1 \\
aug-cc-pVDZ & 2 & 2 & 2 & 0 & 2 \\
aug-cc-pVTZ & 2 & 2 & 1 & 1 & 1 \\
aug-cc-pvQZ & 2 & 2 & 2 & 2 & 1 \\
\hline
\end{tabular}

Table 12. Dependence on methods and basis sets for the number of non-nuclear attractors (NNA) in $\mathrm{C}_{2}$.

\begin{tabular}{lccccc}
\hline & HF & DFT(B3LYP) & MP2 & CCSD & CCSD(T) \\
\hline 6-311G++(d,p) & 1 & 0 & 0 & 0 & 2 \\
cc-pVDZ & 1 & 2 & 0 & 0 & 1 \\
cc-pVTZ & 1 & 1 & 1 & 1 & 1 \\
cc-pVQZ & 1 & 2 & 2 & 2 & 1 \\
aug-cc-pVDZ & 1 & 2 & 0 & 0 & 2 \\
aug-cc-pVTZ & 1 & 1 & 1 & 1 & 1 \\
aug-cc-pvQZ & 1 & 2 & 2 & 2 & 1 \\
\hline
\end{tabular}

\subsection{Comparison between $\mathrm{Li}_{2}$ and $\mathrm{Be}_{2}$}

Bonding nature of first two simplest diatomic molecules is significantly different from each other. We have compared the bonding in $\mathrm{Li}_{2}$ and $\mathrm{Be}_{2}$ based on the parameters derived in the previous section. Noncovalent index (NCI) plots have been used in the same context. Results are summarized in Table 14.

$\mathrm{Li}_{2}$ is 7 times more strongly bound than $\mathrm{Be}_{2}$. On the contrary, electron density at bond critical point for $\mathrm{Be}_{2}$ (0.0373 a.u) is greater than $\mathrm{Li}_{2}$. A recent theoretical report $^{95}$ showed that $\mathrm{Be}-\mathrm{Be}$ bond in radical ligand (L:

Be-Be: L) becomes up to 300 times stronger than isolated $\mathrm{Be}_{2}$. With $\mathrm{L}=[\mathrm{CN}]$, the strength of the $\mathrm{Be}-\mathrm{Be}$ bond was calculated to be $330 \mathrm{~kJ} / \mathrm{mol}$, strongest $\mathrm{Be}-\mathrm{Be}$ bond reported in the literature so far.

The variation of electron density and gradient norm of electron density, along the bond axis have been plotted for $\mathrm{Li}_{2}$ and $\mathrm{Be}_{2}$ (Figure 3) using the Multiwfn 3.6 program. In the case of $\mathrm{Li}_{2}$, the presence of electron density maximum in between $\mathrm{Li}-\mathrm{Li}$ region is indicative of Non-nuclear attractor (NNA). We have not found any such NNA in $\mathrm{Be}_{2}$ at the equilibrium bond distance. However, a slight change in bond distance could lead to NNA in between Be-Be bond. Laplacian of electron density at the bond critical point 
Table 13. Number of NNA generated from CASSCF calculation on $\mathrm{B}_{2}$ and $\mathrm{C}_{2}$.

\begin{tabular}{lcc}
\hline & $\mathrm{B}_{2}$ & $\mathrm{C}_{2}$ \\
\hline 6-311G++(d,p) & 0 & 0 \\
cc-pVDZ & 0 & 0 \\
cc-pVTZ & 2 & 1 \\
cc-pVQZ & 0 & 0 \\
aug-cc-pVDZ & 0 & 0 \\
aug-cc-pVTZ & 2 & 1 \\
aug-cc-pVQZ & 0 & 0 \\
\hline
\end{tabular}

for $\mathrm{Li}_{2}$ is positive. Positive Laplacian indicates the 'closed-shell' interaction. The central subspace has a wide region characterized by a negative Laplacian thereby indicating a concentration of charge and a dominance of the stabilizing potential energy contribution in the $\mathrm{Li}-\mathrm{Li}$ internuclear region. As a consequence, the properties at $(3,-1)$ critical point are no longer directly related to the nature of $\mathrm{Li}-\mathrm{Li}$ interaction.

On the other hand, in $\mathrm{Be}_{2}$ a large negative portion (dotted red lines) in between the $\mathrm{Be}-\mathrm{Be}$ nucleus which indicates electron accumulation in that region as can be seen from the variation of gradient norm of electron density $(|\nabla \rho|)$ along the internuclear axis (Figure 4) and the 2D contour plot (Figure 5). Similar plots for $\mathrm{HF}$ and $\mathrm{LiH}$ are given in Supplementary Information (Figure SF5).

\subsection{Non-covalent index plot for $\mathrm{Li}_{2}$ and $\mathrm{Be}_{2}$}

The non-covalent interaction (NCI) method, which is also known as reduced density gradient (RDG) method, is a very popular method for studying weak interaction which actually deals with electron density $\rho(r)$ and reduced density gradient $s(r)$.

$s(r)=\frac{1}{2\left(3 \pi^{2}\right)^{1 / 3}} \frac{|\nabla \rho(r)|}{\rho(r)^{4 / 3}}$

At the bond critical point where the first derivative of electron density goes to zero $[\nabla \rho(r)=0]$, the reduced density gradient also becomes zero. So the intra/intermolecular interaction can be identified using the plot of reduced density gradient and electron density. The sign of the second eigenvalue of the Hessian matrix $\left(\lambda_{2}\right)$ is utilized to distinguish between types of interactions. $\lambda_{2}<0$ characterizes bonding interaction; $\lambda_{2}>0$ non-bonding interaction i.e. steric repulsion. Finally, van der Waals interactions are characterized by a negligible density overlap that gives $\lambda_{2} \lesssim 0$. This method, called NCI plot, was developed by Yang's group. ${ }^{72-74}$

The NCI plot for $\mathrm{Li}_{2}$ shows two troughs, almost overlapping (Figure 6). As previously discussed $\mathrm{Li}_{2}$ has two bond critical points. Both the bond critical points have similar electron density, the two troughs are the result of two existing BCP's. In $\mathrm{Be}_{2} \mathrm{NCI}$ plot one trough is observed around -0.028 a.u.

Table 14. Comparison in bond length, bond dissociation energy, electron density at $\mathrm{BCP}(\rho)$ and Laplacian of electron density at BCP $\left(\nabla^{2} \rho\right)$ of $\mathrm{Li}_{2}$ and $\mathrm{Be}_{2}$ (CCSD (T)(Full)/aug-cc-pVTZ).

\begin{tabular}{lcccc}
\hline & Bond length $(\AA)$ & Bond dissociation energy (kJ/mol) & $\rho$ (a.u) & $\nabla^{2} \rho($ a.u $)$ \\
\hline $\mathrm{Li}_{2}$ & 2.673 & 82.4 & 0.0139 & +0.0089 \\
$\mathrm{Be}_{2}$ & 2.453 & 11.1 & 0.0373 & -0.0462 \\
\hline
\end{tabular}
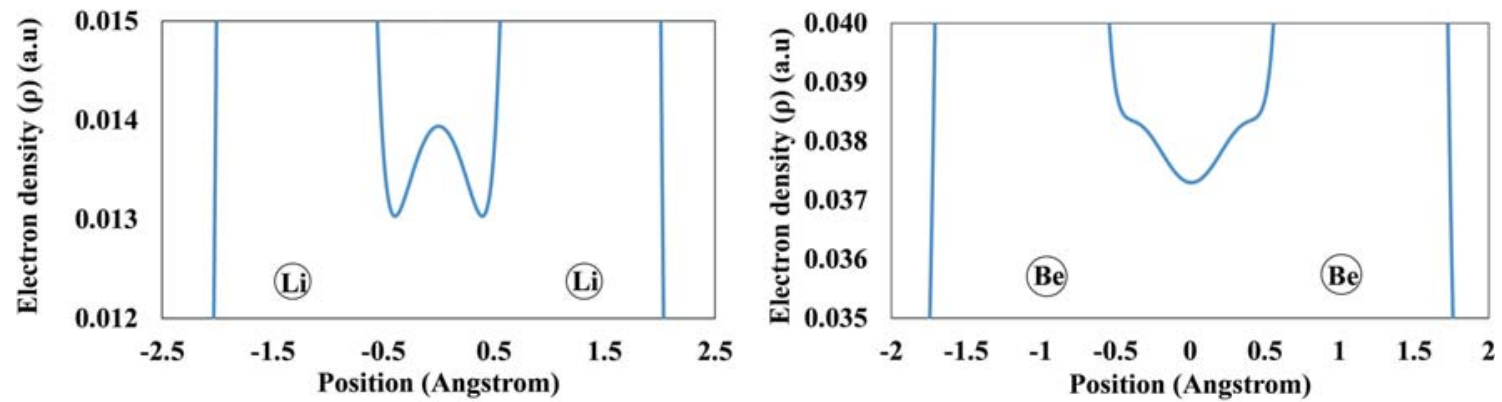

Figure 3. Variation of electron density $(\rho)$ along the internuclear axis of $\mathrm{Li}_{2}$ (left, with $\mathrm{NNA}$ ) and $\mathrm{Be}_{2}$ (right, without NNA). 

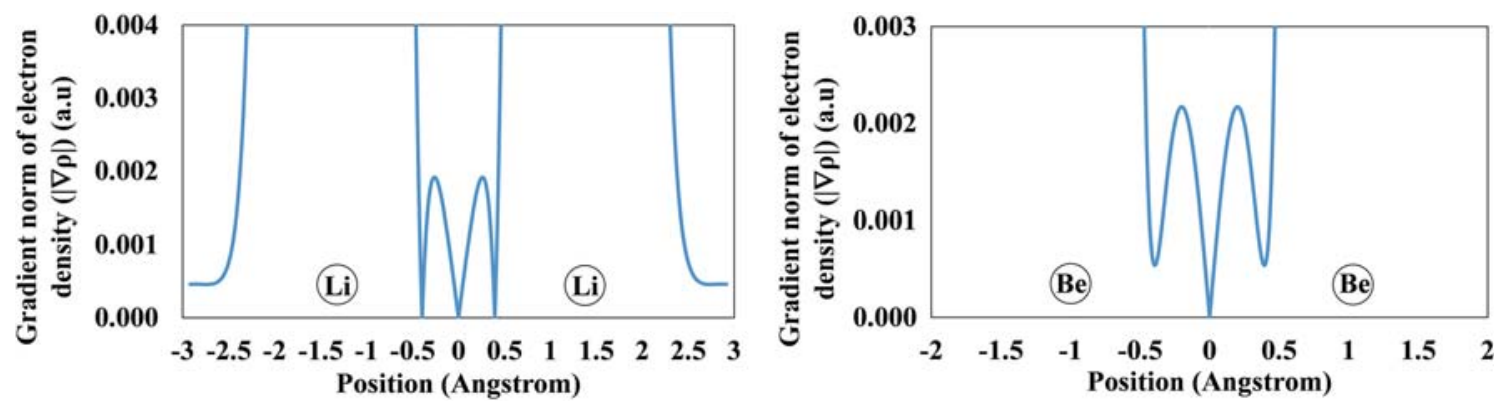

Figure 4. Variation of gradient norm of electron density $(|\nabla \rho|)$ along the internuclear axis of $\mathrm{Li}_{2}$ (left, with 3 critical points) and $\mathrm{Be}_{2}$ (right, with one critical point).

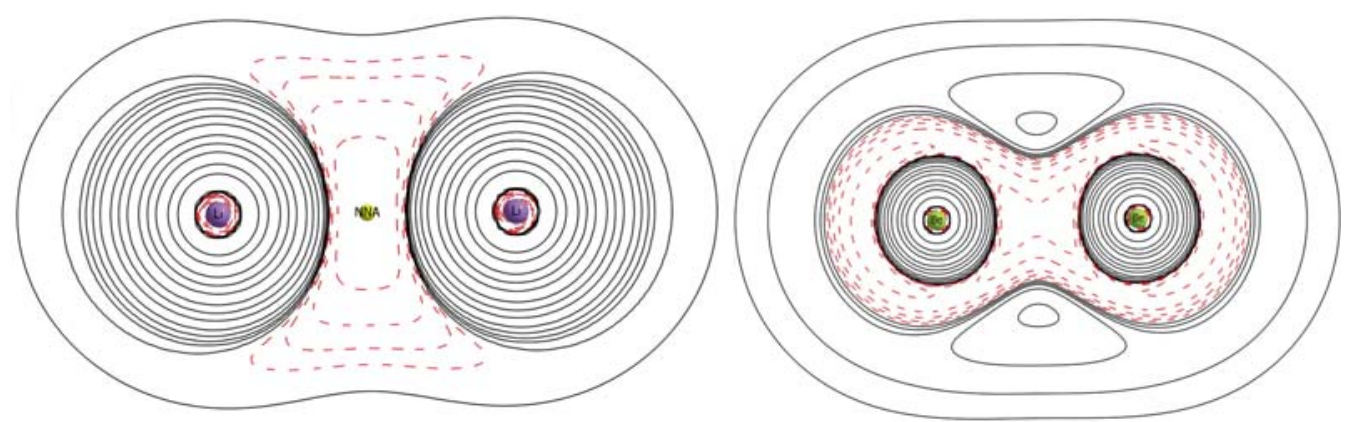

Figure 5. 2D contour plot of Laplacian of electron density of $\mathrm{Li}_{2}$ (left) and $\mathrm{Be}_{2}$ (right). Black solid lines denote positive values and red dotted lines denote negative values. Calculated using CCSD (T)/aug-cc-pVTZ level of theory.

\subsection{Comparison between $\mathrm{N}_{2}$ and $\mathrm{Ne}_{2}$ based} on electron density contour map

$\mathrm{N}_{2}$ and $\mathrm{Ne}_{2}$ belong to two different regimes of chemical bonding. Electron density at bond critical point of $\mathrm{N}_{2}$ is the highest amongst the Period 2 homonuclear diatomic molecules. $\mathrm{N}_{2}$ shows a highly negative Laplacian value at the bond critical point, indicating its covalent nature. $\mathrm{Ne}_{2}$ is most weakly bound amongst the Period 2 diatomic molecules. Figure 7 shows the differences in the 2D contour plot of electron density between $\mathrm{N}_{2}$ and $\mathrm{Ne}_{2}$. The contour shows the clear differences between the covalent and van der Waals bonds. In case of $\mathrm{Ne}_{2}$ the signature of the individual's atoms electron density is preserved, with negligible amount of overlap between the atoms contours.

\subsection{Comparison between $\mathrm{N}_{2}, \mathrm{O}_{2}$ and $\mathrm{F}_{2}$ based on the Laplacian of electron density contour map}

$\mathrm{N}_{2}, \mathrm{O}_{2}$ and $\mathrm{F}_{2}$ are typically described as having a triple, double and single bonded diatomic molecules. Binding energy, as well as electron density at bond critical point, decreases from $\mathrm{N}_{2}$ to $\mathrm{F}_{2}$. Laplacian of electron density is negative for $\mathrm{N}_{2}(-3.5009)$ and $\mathrm{O}_{2}(-0.9375)$. However for $\mathrm{F}_{2}$, the Laplacian of the electron density $\left(\nabla^{2} \rho\right)$ at the
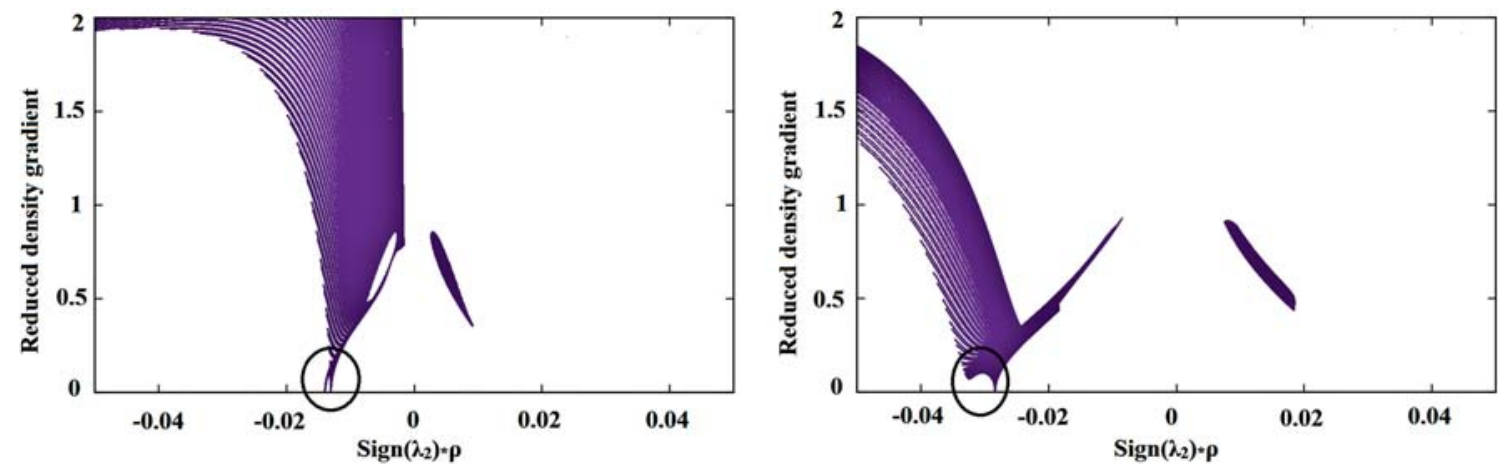

Figure 6. Non-covalent index plots for $\mathrm{Li}_{2}$ (left) and $\mathrm{Be}_{2}$ (right). $\mathrm{X}$-axis is the reduced density gradient and $\mathrm{Y}$-axis is $\operatorname{sign}\left(\lambda_{2}\right) * \rho$. 

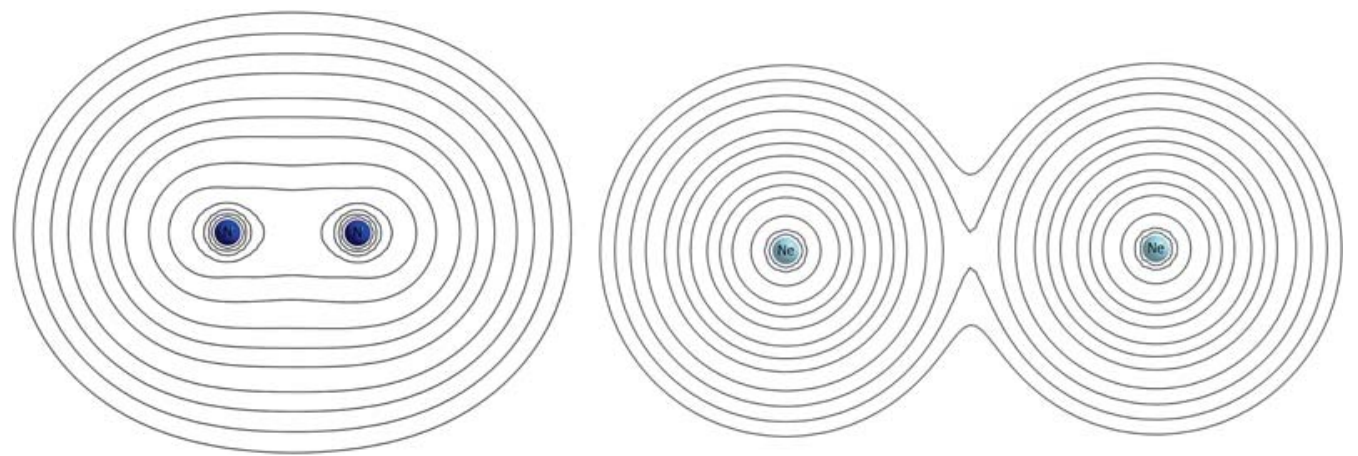

Figure 7. 2D contour of $\rho(\mathrm{r})$ for $\mathrm{N}_{2}$, a typical example of a covalent bond (above) and $\mathrm{Ne}_{2}$, a typical example of van der Waals (below) molecule.

BCP is positive unlike what is expected for shared-shell interaction, a normal covalent bond. Positive $\nabla^{2} \rho$ essentially means electron depletion around the BCP. In a general term, the formation of a covalent bond accumulates electron density around the bond critical points (as can be seen in case of $\mathrm{N}_{2}$ and $\mathrm{O}_{2}$ ), but in $\mathrm{F}_{2}$ where the atoms are very electronegative, electron density is strongly pulled toward the nuclei which essentially weakens the F-F bond. Figure 8 shows the $\nabla^{2} \rho$ contour plots for $\mathrm{N}_{2}, \mathrm{O}_{2}, \mathrm{~F}_{2}$, the contours for $\mathrm{N}_{2}$ and $\mathrm{O}_{2}$ are similar, having large negative values around the internuclear region. Whereas, in $\mathrm{F}_{2}$, the negative $\nabla^{2} \rho$ region is only around the $\mathrm{F}$ atoms, in the internuclear region there is a large positive $\nabla^{2} \rho$ space. This kind of anomaly is also present in $\mathrm{H}_{2} \mathrm{O}_{2} . \nabla^{2} \rho$ at the $\mathrm{O}-\mathrm{O}$ bcp is indeed positive in $\mathrm{H}_{2} \mathrm{O}_{2} \cdot{ }^{96}$ So, sign of $\nabla^{2} \rho$ is not a definitive criterion to differentiate between ionic and covalent interactions. For $\mathrm{F}_{2}$, both $\left|\lambda_{1}\right| \lambda_{3}$ and $|V| / G$ ratios are intermediate range of closed and shared interactions.

\subsection{Potential acting on one electron in a molecule}

Zhao and Yang $^{76}$ showed that the potential acting on one electron in a molecule (PAEM) can give us a clear distinction between the chemical bond and van der
Waals interactions. As we propose all the diatomic molecules are bound by 'chemical bonds', we prefer to use the terminology 'shared' and 'closed' for PAEM analysis. The PAEM is defined as the interaction energy of one electron at local position $\vec{r}$ with the remaining electrons and all the nuclei in a molecular system:

$$
\begin{aligned}
V_{P A E M}(\vec{r})= & -\sum_{A} \frac{Z_{A}}{\left|\vec{r}-\overrightarrow{R_{A}}\right|} \\
& +\frac{1}{\rho(\vec{r})} \int \frac{\rho_{2}\left(\vec{r}, \overrightarrow{r_{2}}\right)}{\left|\vec{r}-\overrightarrow{r_{2}}\right|} d \overrightarrow{r_{2}}
\end{aligned}
$$

where $\mathrm{Z}_{\mathrm{A}}$ and $\overrightarrow{R_{A}}$ are the nuclear charge and position of nucleus A, $\rho(\vec{r})$ the electron density, $\rho_{2}\left(\vec{r}, \overrightarrow{r_{2}}\right)$ is the two-electron density function, that is, the probability function of finding one electron at $\vec{r}$ and another electron at $\overrightarrow{r_{2}}$ simultaneously. $\rho(\vec{r})$ and $\rho_{2}\left(\vec{r}, \overrightarrow{r_{2}}\right)$ are accurately expressed by the electronic wave function. In this work, we have evaluated the wave function at CCSD (t,full)/aug-cc-pVTZ level.

Based on PAEM, $V(\vec{r})$, we can define the force acting on one electron in a molecule (FAEM), which is just the minus of the gradient of the PAEM, that is

$$
F(\vec{r})=-\nabla V(\vec{r})
$$
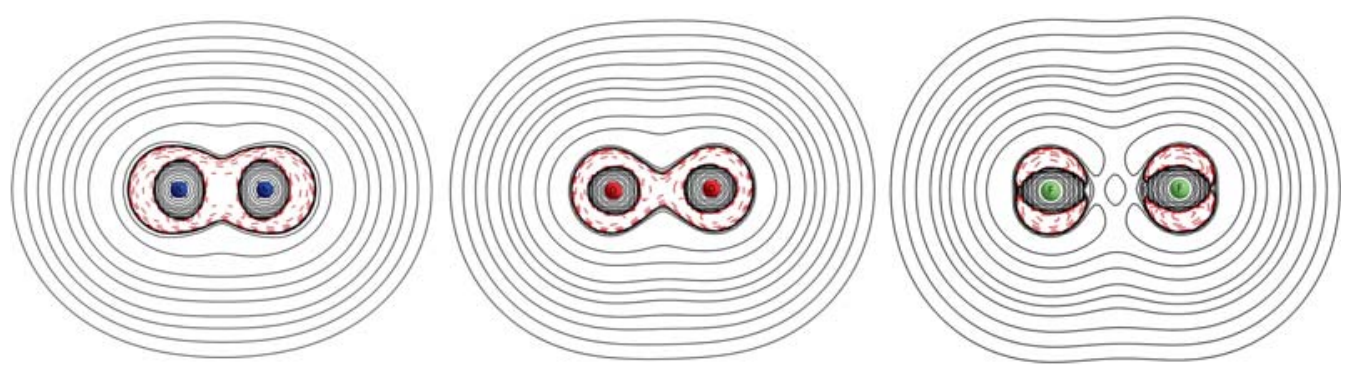

Figure 8. Contour plots of $\nabla^{2} \rho$ of $\mathrm{N}_{2}, \mathrm{O}_{2}$ and $\mathrm{F}_{2}$. Red color denotes the negative region and the black represents the positive region. The internuclear region $\nabla^{2} \rho$ has a large negative value for $\mathrm{N}_{2}$ and $\mathrm{O}_{2}$ (red curves). Whereas for $\mathrm{F}_{2}, \nabla^{2} \rho$ in the internuclear region is positive (black curve). 
Table 15. Molecular orbitals and energy levels for $\mathrm{Be}_{2}$ and $\mathrm{Ne}_{2}$. (Bold values are for filled orbital). Energies are in a.u.

\begin{tabular}{|c|c|c|c|c|c|c|c|c|c|}
\hline \multicolumn{2}{|c|}{ Diatomic molecules } & $\sigma_{1 s}$ & $\sigma_{1 s^{*}}$ & $\sigma_{2 s}$ & $\sigma_{2 s^{*}}$ & $\sigma_{2 p}$ & $\pi_{2 p}$ & $\sigma_{2 p^{*}}$ & $\pi_{2 p^{*}}$ \\
\hline \multirow[t]{2}{*}{$\mathrm{Be}_{2}$} & & -4.731 & -4.731 & -0.405 & -0.238 & 0.005 & 0.008 & 0.024 & 0.036 \\
\hline & $\sigma_{1 s}$ & $\sigma_{1 s^{*}}$ & $\sigma_{2 s}$ & $\sigma_{2 s^{*}}$ & $\sigma_{2 p}$ & & & $\pi_{2 p^{*}}$ & $\sigma_{2 p^{*}}$ \\
\hline $\mathrm{Ne}_{2}$ & -32.779 & -32.779 & -1.934 & -1.933 & -0.855 & & & -0.850 & -0.847 \\
\hline
\end{tabular}
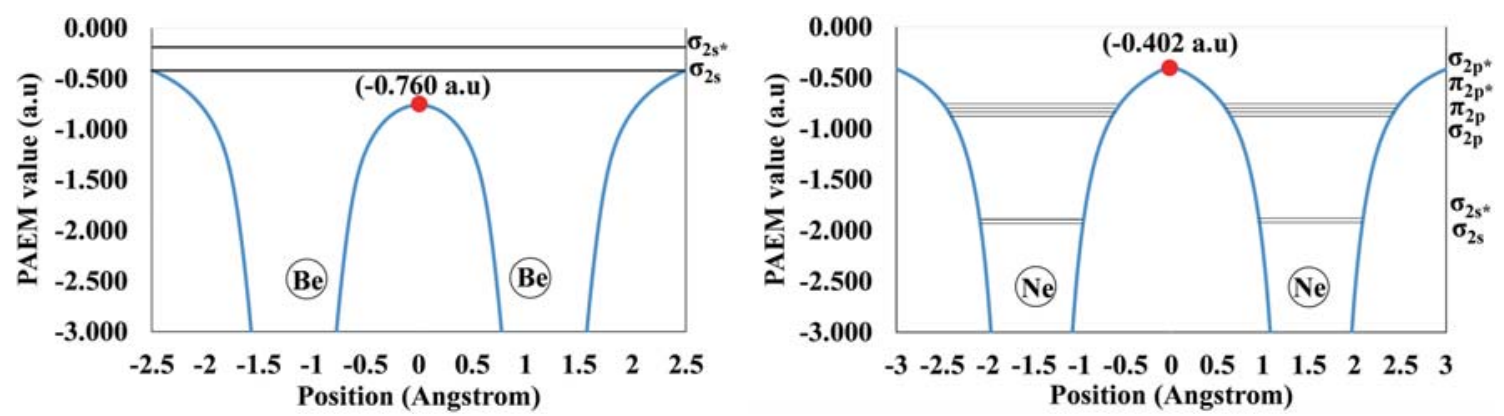

Figure 9. The PAEM-MO diagram along the line connecting two atoms: (a) $\mathrm{Be}_{2}$ molecule, shared shell (chemical bonding) interaction; (b) $\mathrm{Ne}_{2}$ molecule closed-shell (van der Waals) interaction.

Table 16. Potential acting on one electron (PAEM), electrostatic potential (ESP) and electron density at BCP for Period 2 homonuclear diatomic molecules (values are in a.u).

\begin{tabular}{lccccc}
\hline $\begin{array}{l}\text { Diatomic } \\
\text { molecules }\end{array}$ & $\begin{array}{c}\text { PAEM } \\
\text { (a.u) }\end{array}$ & $\begin{array}{c}\text { Energy of the HOMO } \\
\text { (a.u) }\end{array}$ & $\begin{array}{c}\text { Nature of } \\
\text { interaction }\end{array}$ & $\begin{array}{c}\text { ESP } \\
\text { (a.u) }\end{array}$ & $\begin{array}{c}\text { Electron density at BCP } \\
\text { (a.u) }\end{array}$ \\
\hline $\mathrm{Li}_{2}$ & -0.452 & -0.182 & Shared & 0.103 & 0.0130 \\
$\mathrm{Be}_{2}$ & -0.760 & -0.238 & Shared & 0.256 & 0.0373 \\
$\mathrm{~B}_{2}$ & -1.564 & -0.363 & Shared & 0.811 & 0.1247 \\
$\mathrm{C}_{2}$ & -2.484 & -0.457 & Shared & 1.518 & 0.3160 \\
$\mathrm{~N}_{2}$ & -3.240 & -0.614 & Shared & 1.843 & 0.7204 \\
$\mathrm{O}_{2}$ & -2.777 & -0.560 & Shared & 1.448 & 0.5505 \\
$\mathrm{~F}_{2}$ & -1.940 & -0.667 & Shared & 0.809 & 0.3004 \\
$\mathrm{Ne}_{2}$ & -0.402 & -0.847 & Closed & 0.033 & 0.0023 \\
\hline
\end{tabular}

Values of $V(\vec{r})$ and $F(\vec{r})$ at each point of $\vec{r}$ can be worked out with numerical calculations in terms of an $a b$ initio method. A point where $F(\vec{r})$ is equal to zero is called a critical point of the PAEM.

Multiwfn $3.6^{84}$ was used to calculate PAEM. The MO's are calculated at $\operatorname{CCSD}(\mathrm{t})($ full)/aug-cc-pVTZ level given in Table 15. For $\mathrm{Be}_{2}, \sigma 2 \mathrm{~s}$ and $\sigma 2 \mathrm{~s} *$ MO's are above the PAEM barrier $(-0.76$ a.u $\sim-21$ ev), see Figure 9. So the electrons can freely interflow between the two $\mathrm{Be}$ atoms. Whereas in $\mathrm{Ne}_{2}$ all the MOs are below the PAEM barrier $(-0.40$ a.u $\sim-11$ ev). This means that the PAEM barrier in $\mathrm{Ne}_{2}$, separates $\mathrm{Ne}_{2}$ into two $\mathrm{Ne}$ atoms between which the electron interflow does not exist except by tunnelling. A similar analysis has been carried out for other diatomic molecules and the results are provided in Table 16.

\subsection{Total electrostatic potential}

The electrostatic potential, ESP, measures the potential energy that a positive test unit charge (not belonging to the molecular system) gains on being transported from infinity to point $r$ :

$V_{e s p}(\vec{r})=\sum_{A} \frac{Z_{A}}{\left|\vec{r}-\overrightarrow{R_{A}}\right|}-\int \frac{\rho\left(\overrightarrow{r_{2}}\right)}{\left|\vec{r}-\overrightarrow{r_{2}}\right|} d \overrightarrow{r_{2}}$

A runs over all the nuclei of the molecule and $Z_{\mathrm{A}}$ is the nuclear charge of a nucleus at $\mathrm{R}_{\mathrm{A}}$.

$V_{P A E M}(\vec{r})=-V_{E S P}(\vec{r})+\frac{V_{x c}(\vec{r})}{\rho(\vec{r})}$

$V_{x c}$ is the two-electron contribution from the quantum exchange-correlation potential. 

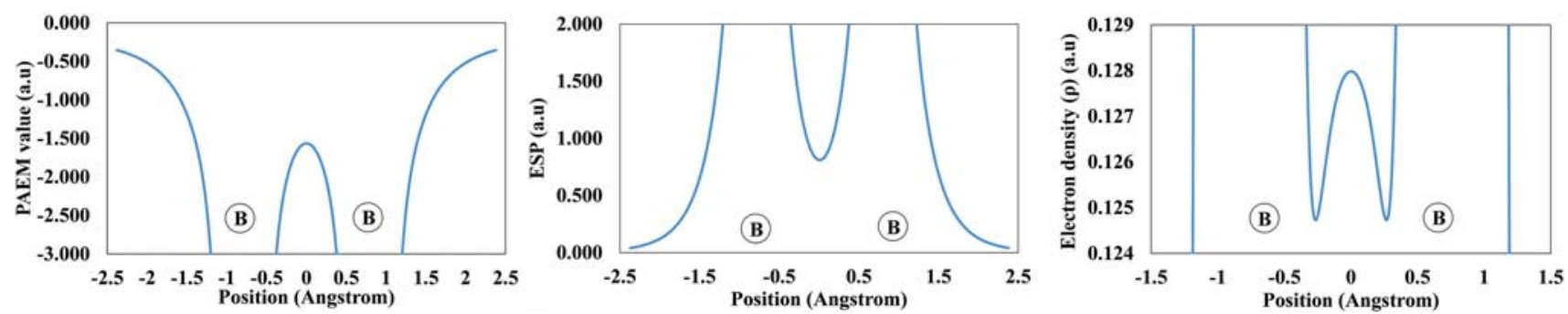

Figure 10. A typical example of PAEM (left), ESP (middle) and electron density (right) at BCP for $\mathrm{B}_{2}$ molecule.

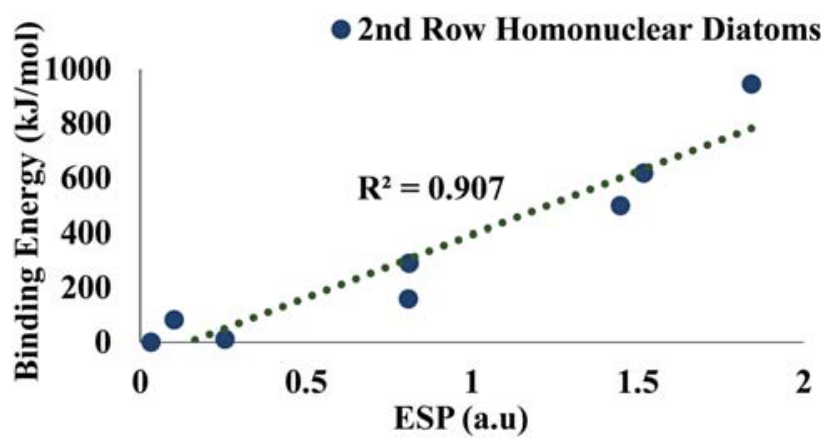

Figure 11. Correlation plot of Binding Energy vs. ESP for Period 2 homonuclear dimer.

$V_{x c}=\frac{1}{\rho(\overrightarrow{r)}} \int \frac{\rho_{x c}\left(r, r_{2}\right)}{\left|\vec{r}-\overrightarrow{r_{2}}\right|} d r_{2}$

From Figure 10, it can be realised that PAEM and ESP are of opposite signs. Electron density shows two minima along the bond for $\mathrm{B}_{2}$ at $\operatorname{CCSD}(\mathrm{T})$ level but the PAEM and ESP shows only one maxima and minima along the internuclear region. In Table 16 PAEM, ESP and electron density values are reported for the Period 2 diatomic molecules. PAEM and ESP are well correlated with each other which indicates quantum exchange-correlation potential scales linearly with the values (Figure SF7, Supplementary Information). For both HLi and HF, the PAEM barrier is lower compared to the major valence bonding orbital in both the cases (Figure SF6, Supplementary Information). Natural resonance theory (NRT) ${ }^{83}$ is used to measure the covalency and ionicity in these bonds. NRT shows $\mathrm{LiH}$ is $85 \%$ ionic and HF is $57 \%$ ionic (Table ST13, Supplementary Information).

For $\mathrm{Li}_{2}$ to $\mathrm{F}_{2}$, except $\sigma_{1 \mathrm{~s}}$ and $\sigma_{1 \mathrm{~s}^{*}}$, all other molecular orbitals are above the PAEM barrier. However, for $\mathrm{Ne}_{2}$ all the energy levels are below the PAEM barrier. In fact, the binding energy correlates well with ESP having $\mathrm{R}^{2}$ of around 0.91 (Figure 11). There is a good correlation between the PAEM and ESP at their critical points between the two atoms and hence between the binding energy and ESP as well.
These are shown in Figures SF7 and SF8 in Supplementary Information. Clearly, the PAEM analysis allows us to compare the bonding in all 8 homonuclear diatomic molecules from Period 2 as one group, unlike the electron density at the BCP based on AIM analysis, in which these had to be grouped into three sets.

\section{Conclusions}

Chemical bonding is indeed a highly complex phenomenon. Period 2 homonuclear diatomic molecules exhibit all the diversity in chemical bonds that can be observed. We can summarize the results of our analysis in the following points:

1. AIM analysis reveals that $\mathrm{Li}_{2}, \mathrm{~B}_{2}$ and $\mathrm{C}_{2}$ have a non-nuclear critical point at the midpoint. For $\mathrm{B}_{2}$ and $\mathrm{C}_{2}$ the appearance of the non-nuclear critical point is sensitive towards the nature of wave functions. The topological properties at the bond critical point for these molecules may not be good indicators of the nature of the interaction.

2. For $\mathrm{N}_{2}, \mathrm{O}_{2}, \mathrm{~F}_{2}$, a typical bond critical point in the internuclear region is found. However, for $F_{2}, \nabla^{2} \rho$ at bond critical point is positive, suggesting electron depletion around the bond critical point. However, the PAEM-MO suggests that $F_{2}$ has a shared-shell (covalent) bond as expected whereas $\mathrm{Ne}_{2}$ has a closed-shell bond. Non-Covalent Index plot also shows closed-shell bonding in $\mathrm{Ne}_{2}$ molecule (Figure SF4, Supplementary Information).

3. To understand two different regimes of bonding namely ionic and covalent bonds, we have analyzed the bonding properties of $\mathrm{LiH}$ and HF. $\nabla^{2} \rho$ plot clearly reflects the differences between the two. For $\mathrm{LiH}, \nabla^{2} \rho$ is positive at $\mathrm{BCP}$, indicating ionic bond whereas, $\nabla^{2} \rho$ negative at $\mathrm{BCP}$ for $\mathrm{HF}$, indicating covalent bond. However, NRT analysis revels HLi is $85 \%$ ionic and $\mathrm{HF}$ is $57 \%$ ionic.

4. Finally, the AIM analysis shows that Period 2 diatomic molecules can be grouped into three different types based on the correlation between 
binding energy and electron density at the $\mathrm{BCP}$. One group $\left(\mathrm{Li}_{2}, \mathrm{~B}_{2}\right.$ and $\left.\mathrm{C}_{2}\right)$ shows NNA in between the two atoms. Both PAEM and ESP analysis indicate only one critical point between the two atoms for all the eight Period 2 diatomic molecules and the values calculated at these critical points have strong correlation with the binding energy covering three orders of magnitude. While this could be used by some to argue that, electrostatics can explain all bonding, one should not forget that these values have been calculated by accurate quantum mechanical methods that take into account electrostatics, dispersion, charge transfer-covalency and exchange repulsion.

\section{Supplementary Information (SI)}

Thirteen tables and nine figures have been provided in the Supplementary Information. Method and basis set dependence of $\mathrm{Be}_{2}$ distance (Table ST1), electron density topological properties of all the Group II homonuclear diatomic molecules (Tables ST2-ST9), electron density on atoms and NNA for $\mathrm{Li}_{2}, \mathrm{~B}_{2}$ and $\mathrm{C}_{2}$ at CCCD/aug-cc-pVTZ level (Table ST10), changes in atomic properties calculated by AIM (Table ST11), ground and low lying excited states of $\mathrm{B}_{2}$ and $\mathrm{C}_{2}$ (Table ST12) and iconicity and covalency of $\mathrm{LiH}$ and HF by NRT analysis (Table ST13). Bar diagram showing percentage errors in diatom dissociation energy at various level (Figure SF1), correlation between binding energy and electron density at the BCP for Period 2 homonuclear diatomic molecules (Figure SF2), $|\lambda 1| / \lambda 3$ and $\mathrm{IVI} / \mathrm{G}$ ratio for homonuclear diatomic molecules (Figure SF3), NCI plot for $\mathrm{Ne}_{2}$ (Figure SF4), variation of the electron density $(\rho)$ along the internuclear axis of $\mathrm{LiH}$ and HF (Figure SF5), PAEM-MO diagram along the line connecting two atoms: for $\mathrm{LiH}$ and HF (Figure SF6), correlation plot between IPAEMI and ESP for homonuclear diatomic molecules of Period 2 (Figure SF7) and correlation plot between binding energy vs. IPAEMI for homonuclear diatomics of Period 2 (Figure SF8). Full Reference of 79 provided in supporting information.

\section{Acknowledgements}

Computational facilities at the Department of Inorganic and Physical Chemistry maintained by Prof. Sai G. Ramesh is acknowledged. AD acknowledges the Indian Institute of Science for the research fellowship.

\section{References}

1. Herzberg G and Mrozowski S 1951 Molecular spectra and molecular structure. I. Spectra of diatomic molecules Am. J. Phys. 19390
2. Huber K P and Herzberg G 1979 Molecular Structure and Molecular Spectra. IV. Constants of Diatomic Molecules (New York: Van Rostrand-Reinhold)

3. Arunan E, Desiraju G R, Klein R A, Sadlej J, Scheiner S, Alkorta I, Clary D C, Crabtree R H, Dannenberg J J, Hobza P, Kjaergaard H G, Legon A C, Mennucci B and Nesbitt D J 2011 Definition of the hydrogen bond (IUPAC Recommendations 2011) Pure Appl. Chem. 83 1637

4. Arunan E, Desiraju G R, Klein R A, Sadlej J, Scheiner S, Alkorta I, Clary D C, Crabtree R H, Dannenberg J J, Hobza P, Kjaergaard H G, Legon A C, Mennucci B and Nesbitt D J 2011 Defining the hydrogen bond: An account (IUPAC Technical Report) Pure Appl. Chem. 831619

5. Legon A C 2010 The halogen bond: An interim perspective Phys. Chem. Chem. Phys. 127736

6. Metrangolo P and Resnati G 2001 Halogen Bonding: A Paradigm in Supramolecular Chemistry Chem. - A Eur. J. 72511

7. Alkorta I, Blanco F, Solimannejad $\mathrm{M}$ and Elguero $\mathbf{J}$ 2008 Competition of hydrogen bonds and halogen bonds in complexes of hypohalous acids with nitrogenated bases J. Phys. Chem. A 11210856

8. Clark T, Hennemann M, Murray J S and Politzer P 2007 Halogen bonding: The $\sigma$-hole J. Mol. Model. 13291

9. Wang W, Ji B and Zhang Y 2009 Chalcogen bond: A sister noncovalent bond to halogen bond J. Phys. Chem. A 1138132

10. Manna D and Mugesh G 2012 Regioselective deiodination of thyroxine by iodothyronine deiodinase mimics: An unusual mechanistic pathway involving cooperative chalcogen and halogen bonding J. Am. Chem. Soc. 1344269

11. Bleiholder C, Werz D B, Köppel H and Gleiter R 2006 Theoretical investigations on chalcogen - chalcogen interactions: What makes these nonbonded interactions bonding? J. Am. Chem. Soc. 1282666

12. Sanz P, Mó O and Yáñez M 2003 Characterization of intramolecular hydrogen bonds and competitive chalcogen-chalcogen interactions on the basis of the topology of the charge density Phys. Chem. Chem. Phys. 52942

13. Del Bene J E, Alkorta I, Sanchez-Sanz G and Elguero J 2011 Structures, energies, bonding, and NMR properties of pnicogen complexes $\mathrm{H}_{2} \mathrm{XP}: \mathrm{NXH}_{2}\left(\mathrm{X}=\mathrm{H}, \mathrm{CH}_{3}\right.$, $\mathrm{NH}_{2}$, OH, F, Cl) J. Phys. Chem. A 11513724

14. Zahn S, Frank R, Hey-Hawkins E and Kirchner B 2011 Pnicogen bonds: A new molecular linker? Chem. Eur. J. 176034

15. Scheiner $\mathrm{S} 2011$ A new noncovalent force: Comparison of $\mathrm{P} \cdots \mathrm{N}$ interaction with hydrogen and halogen bonds J. Chem. Phys. 13494315

16. Mani D and Arunan E 2013 The $\mathrm{X}-\mathrm{C} \cdots \mathrm{Y}(\mathrm{X}=\mathrm{O} / \mathrm{F}$, $\mathrm{Y}=\mathrm{O} / \mathrm{S} / \mathrm{F} / \mathrm{Cl} / \mathrm{Br} / \mathrm{N} / \mathrm{P})$ 'carbon bond' and hydrophobic interactions Phys. Chem. Chem. Phys. 1514377

17. Mani D and Arunan E 2014 The $X-C \cdots \pi(X=F, C l$, Br, Cn) carbon bond J. Phys. Chem. A 11810081

18. Thomas S P, Pavan M S and Guru Row T N 2014 Experimental evidence for 'carbon bonding' in the solid state from charge density analysis Chem. Commun. $\mathbf{5 0} 49$ 
19. Bauzá A, Mooibroek T J and Frontera A 2013 Tetrelbonding interaction: Rediscovered supramolecular force? Angew. Chemie - Int. Ed. 5212317

20. Grabowski S J 2014 Tetrel bond- $\sigma$-hole bond as a preliminary stage of the $\mathrm{S}_{\mathrm{N}} 2$ reaction Phys. Chem. Chem. Phys. 161824

21. Grabowski S J 2014 Boron and other triel Lewis acid centers: From hypovalency to hypervalency ChemPhysChem 152985

22. Kollman P A, Liebman J F and Allen L C 1970 Lithium bond J. Am. Chem. Soc. 921142

23. Ault B S and Pimenter G C 1975 Matrix isolation infrared studies of lithium bonding J. Phys. Chem. 79 621

24. McCleskey T M, Ehler D S, Keizer T S, Asthagiri D N, Pratt L R, Michalczyk R and Scott B L 2007 Beryllium displacement of $\mathrm{H}+$ from strong hydrogen bonds Angew. Chemie 1192723

25. Albrecht L, Boyd R J, Mó O and Yáñez M 2012 Cooperativity between hydrogen bonds and beryllium bonds in (H2O)nBeX2 ( $=1-3, \mathrm{X}=\mathrm{H}, \mathrm{F})$ complexes. A new perspective Phys. Chem. Chem. Phys. 1414540

26. Dunlap B I, Connolly J W D and Sabin J R 1979 On first-row diatomic molecules and local density models J. Chem. Phys. 714993

27. Hajigeorgiou P G 2010 An extended Lennard-Jones potential energy function for diatomic molecules: Application to ground electronic states J. Mol. Spectrosc. 263101

28. Peterson K A, Kendall R A and Dunning T H 1993 Benchmark calculations with correlated molecular wave functions. III. Configuration interaction calculations on first row homonuclear diatomics J. Chem. Phys. 999790

29. Peterson K A, Wilson A K, Woon D E and Dunning Jr. T H 1997 Benchmark calculations with correlated molecular wave functions XII. Core correlation effects on the homonuclear diatomic molecules B2-F2 Theor. Chem. Acc. 97251

30. Binkley J S and Frisch M J 1983 ab initio determination of bond dissociation energies: The first-row diatomics co, N2, NO, O2, and F2 Int. J. Quantum Chem. 24331

31. Painter G S and Averill F W 1982 Bonding in the firstrow diatomic molecules within the local spin-density approximation Phys. Rev. B 261781

32. Ghanty T K and Ghosh S K 1991 Electronegativity and covalent binding in homonuclear diatomic molecules $J$. Phys. Chem. 956512

33. Müller T, Dallos M, Lischka H, Dubrovay $\mathrm{Z}$ and Szalay P G 2001 A systematic theoretical investigation of the valence excited states of the diatomic molecules $\mathrm{B}_{2}, \mathrm{C}_{2}, \mathrm{~N}_{2}$ and $\mathrm{O}_{2}$ Theor. Chem. Acc. 105227

34. Wang J, Clark B J, Schmider H and Smith V H 1996 Topological analysis of electron momentum densities and the bond directional principle: The first-row hydrides, AH, and homonuclear diatomic molecules, A2 Can. J. Chem. 741187

35. Driessler F and Kutzelnigg W 1976 Analysis of the chemical bond Theor. Chim. Acta 431

36. Bradley C C, Sackett C A, Tollett J J and Hulet R G 1995 Evidence of Bose-Einstein condensation in an atomic gas with attractive interactions Phys. Rev. Lett. 751687

37. Bradley C C, Sackett C A and Hulet R G 1997 BoseEinstein condensation of lithium: Observation of limited condensate number Phys. Rev. Lett. 78985

38. Herzberg G 1929 Zum Aufbau der zweiatomigen Moleküle Zeitschrift für Phys. 57601

39. Herzberg L 1933 Über ein neues Bandensystem des Berylliumoxyds und die Struktur des Be O-Moleküls Zeitschrift für Phys. 84571

40. Bondybey V E and English J H 1984 Laser vaporization of beryllium: Gas phase spectrum and molecular potential of Be2 J. Chem. Phys. 80568

41. Merritt J M, Bondybey V E and Heaven M C 2009 Beryllium Dimer-Caught in the act of bonding Science 3241548

42. Douglas A E and Herzberg G 1940 Spectroscopic evidence of the B2 molecule and determination of its structure Can. J. Res. 18165

43. Graham W R M and Weltner W 1976 B atoms, B2 and H2BO molecules: ESR and optical spectra at $4{ }^{\circ} \mathrm{K} J$. Chem. Phys. 651516

44. Dupuis M and Liu B 1978 The ground electronic state of $\mathrm{B}_{2}$ J. Chem. Phys. 682902

45. Langhoff S R and Bauschlicher Jr C W 1991 Theoretical study of the spectroscopy of $\mathrm{B}_{2}$ J. Chem. Phys. 955882

46. Boggio-Pasqua M, Halvick P, Rayez M-T, Rayez J-C and Robbe J-M $1998 \mathrm{Ab}$ initio study of the potential energy surfaces for the reaction $\mathrm{C}+\mathrm{CH} \rightarrow \mathrm{C}_{2}+\mathrm{HJ}$. Phys. Chem. A 1022009

47. Martin M 1992 C2 spectroscopy and kinetics J. Photochem. Photobiol. A Chem. 66263

48. Van Orden A and Saykally R J 1998 Small carbon clusters: Spectroscopy, structure, and energetics Chem. Rev. 982313

49. Boggio-Pasqua M, Voronin A I, Halvick P and Rayez J-C 2000 Analytical representations of high level ab initio potential energy curves of the C2 molecule $J$. Mol. Struct. THEOCHEM 531159

50. Weltner Jr W and Van Zee R J 1989 Carbon molecules, ions, and clusters Chem. Rev. 891713

51. Douay M, Nietmann R and Bernath P F 1988 The discovery of two new infrared electronic transitions of C2: B1 $\Delta \mathrm{g}-\mathrm{A} 1 \Pi \mathrm{u}$ and $\mathrm{B}^{\prime} 1 \Sigma \mathrm{g}+-\mathrm{A} 1 \Pi \mathrm{u}$ J. Mol. Spectrosc. 131261

52. Douay M, Nietmann R and Bernath P F 1988 New

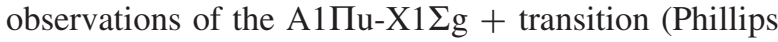
system) of C2 J. Mol. Spectrosc. 131250

53. Pradhan A D, Partridge H and Bauschlicher C W 1994 The dissociation energy of $\mathrm{CN}$ and $\mathrm{C} 2 \mathrm{~J}$. Chem. Phys. 1013857

54. Mulliken R S 1939 Note on electronic states of diatomic carbon, and the carbon-carbon bond Phys. Rev. 56778

55. Su P, Wu J, Gu J, Wu W, Shaik S and Hiberty P C 2011 Bonding conundrums in the $\mathrm{C} 2$ molecule: A valence bond study J. Chem. Theory Comput. 7121

56. Shaik S, Danovich D, Wu W, Su P, Rzepa H S and Hiberty P C 2012 Quadruple bonding in C 2 and analogous eight-valence electron species Nat. Chem. 4 195 
57. von RaguéSchleyer P, Maslak P, Chandrasekhar J and Grev R S 1993 Is a CC quadruple bond possible? Tetrahedron Lett. 346387

58. Lofthus A and Krupenie P H 1977 The spectrum of molecular nitrogen J. Phys. Chem. Ref. Data 6113

59. Huber K-P 2013 Molecular Spectra and Molecular Structure: IV. Constants of Diatomic Molecules (Location: Springer Science \& Business Media)

60. Krupenie P H 1972 The spectrum of molecular oxygen J. Phys. Chem. Ref. Data 1423

61. Matsunaga F M and Watanabe K 1967 Total and photoionization coefficients and dissociation continua of $\mathrm{O}_{2}$ in the 580-1070 $\AA$ region Sci. Light 1631

62. Gale H G and Monk G S 1924 The spectrum of fluorine Astrophys. J. 59125

63. Gale H G and Monk G S 1929 The band spectrum of fluorine Astrophys. J. 6977

64. Andrychuk D 1951 The Raman spectrum of fluorine Can. J. Phys. 29151

65. Tanaka Y and Yoshino K 1972 Absorption spectra of $\mathrm{Ne} 2$ and HeNe molecules in the vacuum-uv region $J$. Chem. Phys. 572964

66. Pauling L 1960 The Nature of the Chemical Bond (Ithaca, NY: Cornell University Press)

67. Bader R F W, Keaveny I and Cade P E 1967 Molecular charge distributions and chemical binding. II. First-row diatomic hydrides, AH J. Chem. Phys. 473381

68. Bader R F W 1990 Atoms in Molecules: A Quantum Theory (New York: Oxford University Press)

69. Popelier P L A, Aicken F M and O'Brien S E 2000 Atoms in molecules Chem. Model. Appl. Theory 1143

70. Amezaga N J M, Pamies S C, Peruchena N M and Sosa G L 2009 Halogen bonding: A study based on the electronic charge density J. Phys. Chem. A 114552

71. Cremer D and Kraka E 1984 Chemical bonds without bonding electron density-Does the difference electron-density analysis suffice for a description of the chemical bond? Angew. Chem. Int. Ed. Eng. 23627

72. Johnson E R, Keinan S, Mori-Sanchez P, ContrerasGarcia J, Cohen A J and Yang W 2010 Revealing noncovalent interactions J. Am. Chem. Soc. 1326498

73. Contreras-García J, Yang W and Johnson E R 2011 Analysis of hydrogen-bond interaction potentials from the electron density: Integration of noncovalent interaction regions J. Phys. Chem. A 11512983

74. Contreras-García J, Johnson E R, Keinan S, Chaudret R, Piquemal J-P, Beratan D N and Yang W 2011 NCIPLOT: A program for plotting noncovalent interaction regions J. Chem. Theory Comput. 7625

75. Zhao D-X and Yang Z-Z 2014 Theoretical exploration of the potential and force acting on one electron within a molecule J. Phys. Chem. A 1189045

76. Zhao D and Yang Z 2014 Investigation of the distinction between van der Waals interaction and chemical bonding based on the PAEM-MO diagram $J$. Comput. Chem. 35965

77. Zhao D, Gong L and Yang Z 2002 Exploration of the potential acting on an electron within diatomic molecules Chin. Sci. Bull. 47635

78. Bartashevich E and Tsirelson V 2018 A comparative view on the potential acting on an electron in a molecule and the electrostatic potential through the typical halogen bonds J. Comput. Chem. 39573

79. Frisch M J, Trucks G W, Schlegel H B, Scuseria G E, Robb M A, Cheeseman J R, Scalmani G, Barone V, Mennucci B and Petersson G A 2009 Gaussian 09 Revision D. 01, 2009 (Wallingford CT: Gaussian Inc.)

80. Werner H J, Knowles P J, Knizia G, Manby F R, Schütz M, Celani P, Györffy W, Kats D, Korona T and Lindh R 2015 MOLPRO, Version 2015.1, a Package of Ab Initio Programs (Cardiff, Wales, UK: Univ. Cardiff Chem. Consult.)

81. Keith T A 2014 AIMAll (Version 14.11.23), TK Gristmill Software, Overland Park KS, USA

82. Glendening E D, Landis C R and Weinhold F 2013 NBO 6.0: Natural bond orbital analysis program $J$. Comput. Chem. 341429

83. Glendening E D and Weinhold F 1998 Natural resonance theory: I. General formalism J. Comput. Chem. 19593

84. Lu T and Chen F 2012 Multiwfn: A multifunctional wavefunction analyzer J. Comput. Chem. 33580

85. Bacskay G B and Nordholm S 2017 Covalent bonding in the hydrogen molecule J. Phys. Chem. A 1219330

86. Aziz R A and Slaman M J 1989 The Ne-Ne interatomic potential revisited Chem. Phys. 130187

87. Emsley J 1998 The Elements (Oxford; New York: Clarendon Press; Oxford University Press)

88. Heaven M C, Bondybey V E, Merritt J M and Kaledin A L 2011 The unique bonding characteristics of beryllium and the Group IIA metals Chem. Phys. Lett. 5061

89. Luo Y-R 2003 Handbook of Bond dissociation energies In Organic Compounds (Boca Raton: CRC Press) p. 89

90. Sudhakar P V and Lammertsma K 1993 Bond properties of Be3-7 clusters J. Chem. Phys. 997929

91. Cao W L, Gatti C, MacDougall P J and Bader R F W 1987 On the presence of non-nuclear attractors in the charge distributions of Li and Na clusters Chem. Phys. Lett. 141380

92. Vries R Y de, Briels W J, Fell D, Velde G te and Baerends E J 1996 Charge density study with the Maximum Entropy Method on model data of silicon. A search for non-nuclear attractors Can. J. Chem. 74 1054

93. Iversen B B, Larsen F K, Souhassou M and Takata M 1995 Experimental evidence for the existence of nonnuclear maxima in the electron-density distribution of metallic beryllium. A comparative study of the maximum entropy method and the multipole refinement method Acta Crystallogr. Sect. B $\mathbf{5 1 5 8 0}$

94. Platts J A, Overgaard J, Jones C, Iversen B B and Stasch A 2010 First experimental characterization of a non-nuclear attractor in a dimeric magnesium (I) compound J. Phys. Chem. A 115194

95. Brea O and Corral I 2018 Super strong Be-Be bonds: Theoretical insight into the electronic structure of BeBe complexes with radical ligands J. Phys. Chem. A 1222258

96. Mó O, Yáñez M, Eckert-Maksić M, Maksić Z B, Alkorta I and Elguero J 2005 Periodic trends in bond dissociation energies. A theoretical study J. Phys. Chem. A 1094359 